\title{
A field study of the individual and combined effect of ventilation rate and lighting conditions on pupils' performance
}

Hviid, Christian A.; Pedersen, Christian ; Dabelsteen, Kent Helmann

Published in:

Building and Environment

Link to article, DOI:

10.1016/j.buildenv.2019.106608

Publication date:

2020

Document Version

Peer reviewed version

Link back to DTU Orbit

Citation (APA):

Hviid, C. A., Pedersen, C., \& Dabelsteen, K. H. (2020). A field study of the individual and combined effect of ventilation rate and lighting conditions on pupils' performance. Building and Environment, 171, [106608]. https://doi.org/10.1016/j.buildenv.2019.106608

\section{General rights}

Copyright and moral rights for the publications made accessible in the public portal are retained by the authors and/or other copyright owners and it is a condition of accessing publications that users recognise and abide by the legal requirements associated with these rights.

- Users may download and print one copy of any publication from the public portal for the purpose of private study or research.

- You may not further distribute the material or use it for any profit-making activity or commercial gain

- You may freely distribute the URL identifying the publication in the public portal 


\section{Journal Pre-proof}

A field study of the individual and combined effect of ventilation rate and lighting conditions on pupils' performance

Christian A. Hviid, Christian Pedersen, Kent Helmann Dabelsteen

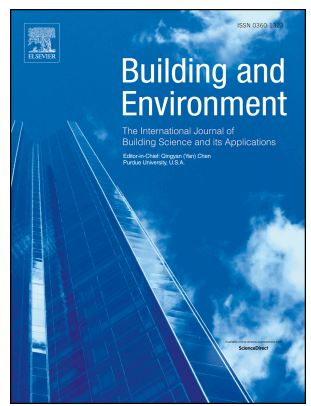

PII:

S0360-1323(19)30820-0

DOI: https://doi.org/10.1016/j.buildenv.2019.106608

Reference: BAE 106608

To appear in: Building and Environment

Received Date: 17 August 2019

Revised Date: 15 December 2019

Accepted Date: 16 December 2019

Please cite this article as: Hviid CA, Pedersen C, Dabelsteen $\mathrm{KH}, \mathrm{A}$ field study of the individual and combined effect of ventilation rate and lighting conditions on pupils' performance, Building and Environment, https://doi.org/10.1016/j.buildenv.2019.106608.

This is a PDF file of an article that has undergone enhancements after acceptance, such as the addition of a cover page and metadata, and formatting for readability, but it is not yet the definitive version of record. This version will undergo additional copyediting, typesetting and review before it is published in its final form, but we are providing this version to give early visibility of the article. Please note that, during the production process, errors may be discovered which could affect the content, and all legal disclaimers that apply to the journal pertain.

(C) 2019 Published by Elsevier Ltd. 


\section{A field study of the individual and combined effect of ventilation rate}

\section{2 and lighting conditions on pupils' performance}

3

4

5

6

7

Christian A. Hviid ${ }^{a}{ }$, Christian Pedersen $^{b}$, Kent Helmann Dabelsteen ${ }^{c}$

Affiliations:

${ }^{a}$ Technical University of Denmark, Dept. of Civ Eng, Brovej building 118, DK-2800 Kgs. Lyngby, Denmark cah@byg.dtu.dk

${ }^{b}$ Technical University of Denmark, Dept. of Civ Eng, Brovej building 118, DK-2800 Kgs. Lyngby, Denmark, s133593@student.dtu.dk

${ }^{c}$ Technical University of Denmark, Dept. of Civ Eng, Brovej building 118, DK-2800 Kgs. Lyngby, Denmark, s123626@student.dtu.dk

${ }^{*}$ Corresponding author

\section{Abstract}

A field lab study was conducted to determine how much the indoor climate parameters, ventilation and lighting, influence children's academic abilities. The study involved 92 children, aged 10-12 years, who over four weeks answered a questionnaire and three different performance tests, which measured their processing speed, concentration, logical reasoning and math solving abilities. An experimental design was constructed to test the effect of changing the lighting from constant warm light with $2900 \mathrm{~K}$ and 450 lux to a dynamic cool light with a maintained correlated colour temperature average of $4900 \mathrm{~K}$ and 750 lux. The change was tested at both low ( $3.9 \mathrm{l} / \mathrm{s}$ per person) and high ventilation rate $(10.6 \mathrm{l} / \mathrm{s}$ per person). The results showed that processing speed $(6.6 \%, \mathrm{P}<0.001)$, concentration $(8.3 \%, \mathrm{P}<0.001)$ and math skills $(11.8 \%, \mathrm{P}<0.006)$, improved the most in the combined scenario with high ventilation rate and dynamic cool lighting. The logical reasoning test did not show any significant changes. The questionnaire 
results of the pupils' perception of the indoor environment suggested that they were satisfied in general, but the indoor environmental changes had only very limited effect on how they perceived the classroom. The combination of dynamic lighting and increased ventilation rate indicated a boosted positive impact on the speed and concentration of the children which means that future renovations would benefit from a holistic design including both of these factors.

Keywords: schools, ventilation, lighting, productivity, indoor climate

\section{Introduction}

The scientific evidence is growing that there are correlations between the indoor environment and people's health, well-being and cognitive performance. In the context of the cognitive process of learning, the indoor environment plays a key role in the pupil's abilities to absorb and process knowledge. This has sparked a number of studies trying to quantify the influence of different indoor environmental factors, like ventilation rate [1-4], natural light [5], artificial light [6,7], temperature [8] and acoustics [9-11].

Most of the body of scientific work on school children and performance is related only to one indoor climate parameter, but some researchers have taken a more holistic approach and even included classroom and school design [12-14]. The holistic approach by Barrett et al. [15] showed that pupil's learning progress in the UK can be attributed partly to the indoor climate (49\%), partly to other "softer" values like classroom design (51\%). Among the indoor climate parameters, Barrett ranked the lighting conditions to be most influential, both natural and artificial, then air quality, then temperature. In this study we focused on lighting conditions and ventilation rate as temperature is not controlled in a large share of schools, except through shading and ventilation rate. Lighting and ventilation are factors that 
are often targeted during refurbishment, and the planning prioritization process will benefit from a deeper understanding of the individual and combined effect of these measures.

In terms of combined measures, Wargocki and Wyon [8] made a crossover study investigated the effect of raised ventilation rates and temperatures on pupils' performance in schoolwork. When increasing the ventilation rate from $5 \mathrm{~L} /($ s person) to $10 \mathrm{~L} /($ s person), the performance in four out of eight given tasks resembling schoolwork showed an improvement. The same result was shown for lowering the indoor air temperature from $25^{\circ} \mathrm{C}$ to $20^{\circ} \mathrm{C}$. The improvement was mainly in terms of the speed at which the tasks were performed and there was almost no effect on the amount of errors made. Petersen et al. [4] made a similar study concerning only ventilation rate. It showed a significant increase in four out of four given tests in a double blind crossover intervention where the ventilation rate was increased from 1.7 to 6.6 L/s per person.

In terms of lighting conditions, several studies have shown that lighting affects people's health, mood, well-being and alertness. In terms of mood, Knez and Kers [16] found that young test subjects (about 23 years old) were inclined to keep their negative mood when subjected to correlated colour temperature (CCT) $3000 \mathrm{~K}$ rather than $4000 \mathrm{~K}$ at the illuminance intensity of approx. 500 lux.

Similar effects were found in a crossover experiment made by the Surrey Sleep Research Centre in 2008 [17] showing the effect of blue-enriched white light. During the experiment, half of the study group was exposed to normal white light $(4000 \mathrm{~K})$ while the rest was exposed to blue-enriched white light (17000 K). The $17000 \mathrm{~K}$ light source had a significant positive effect on the participants' alertness, mood, performance, evening fatigue, irritability, concentration, sleep quality and eye discomfort. A study by Mott [7] found that light qualities of illumination and colour temperature had a significant effect on $3^{\text {rd }}$ graders' oral reading performance. The experiment involved 84 children who were exposed to either dynamic light, with an average maintained colour temperature of $6500 \mathrm{~K}$ and illuminance of 1000 lux, or normal light at 500 lux and with constant $3500 \mathrm{~K}$. Sleegers at al. [18] found evidence that dynamic 
lighting had a positive effect on the pupil's concentration. The underlying hypothesis of dynamic lighting is that the circadian cycle of humans is influenced by the wavelengths and luminosity of the surrounding environment $[19,20]$ and by mimicking the outdoor lighting conditions, dynamic lighting - also referred to as human-centric lighting - provides better well-being.

The majority of published work related to school children and performance focuses on only one indoor climate parameter at a time, but the indoor climate is multi-faceted. Thus, the purpose of this study is to gauge, by experimental design, both the individual and combined effect of two indoor climate parameters: ventilation rate and lighting conditions. These parameters are known from previous studies to affect work performance individually, but this study will contribute to the very limited knowledge base on what happens when they work together to create the overall indoor environment. The motivation was to be able to separate the work performance effect of two essential measures in order to provide a better planning tool for indoor environmental quality in classrooms.

Consequently, the hypothesis of this study was: there is a significant positive effect in the pupils' performance when undertaking tasks mimicking the cognitive processes involved in learning as well as satisfaction with the indoor environment, when their classroom indoor environment is changed from having low ventilation rates and constant warm lighting, to higher ventilation rates and dynamic cool lighting. In addition, we hypothesized that the combined effect of lighting and ventilation does not add up nor boost each other. Rather we hypothesized that a certain cancellation effect would occur in the combined test scenarios.

\section{Experimental design}

The aim of the experiment was to detect the individual and combined effect that changing ventilation and lighting have on the performance of the pupils. The experiment was designed in such a way that the effect of the variables could be gauged individually, but also as a combined effect of both variables. 
Table 1 lists the scenarios that were tested and the naming convention. The tested ventilation rates reflect indoor climate category I (10 l/s person) \& III (4 I/s person) [21]. The lighting conditions are determined by the physical properties and proprietary dynamic algorithms of the lighting system. The time plan and execution order of the scenarios is detailed in .

\section{Table 1}

The five contrasting scenarios with naming convention. The test conditions are explained in detail in Section 3.

\begin{tabular}{llll}
\hline Scenario & Test condition A & Test condition B & Description \\
\hline 1 & $3.91 / s_{-}$ & $3.91 / s_{-}$ & Effect of changing to dynamic cool lighting \\
& $2900 \mathrm{~K}$ & $4900 \mathrm{~K}$ & at low ventilation rates \\
\hline 2 & $10.6 \mathrm{l} / \mathrm{s}_{-}$ & $10.6 \mathrm{l} / \mathrm{s}_{-}$ & Effect of changing to dynamic lighting \\
& $2900 \mathrm{~K}$ & $4900 \mathrm{~K}$ & at high ventilation rates \\
\hline 3 & $3.91 / \mathrm{s}_{-}$ & $10.6 \mathrm{l} / \mathrm{s}_{-}$ & Effect of changing to high ventilation rate when \\
& $2900 \mathrm{~K}$ & $2900 \mathrm{~K}$ & lighting is constant and warm \\
\hline 4 & $3.91 / \mathrm{s}_{-}$ & $10.6 \mathrm{l} / \mathrm{s}_{-}$ & Effect of changing to high ventilation rate when \\
& $4900 \mathrm{~K}$ & $4900 \mathrm{~K}$ & lighting is cool and dynamic \\
\hline 5 & $3.91 / \mathrm{s}_{-}$ & $10.6 \mathrm{l} / \mathrm{s}_{-}$ & Effect of both dynamic cool lighting and high \\
& $2900 \mathrm{~K}$ & $4900 \mathrm{~K}$ & ventilation rate
\end{tabular}

\subsection{Cross-over design}

102 The experimental design was inspired by Petersen et al. [4] who conducted a double-blind $2 \times 2$ crossover experiment with high and low ventilation rates in four classrooms. That study took 2 weeks to execute plus one rehearsal week and one baseline week. A comparable crossover experiment with two ventilation rates and two lighting settings creates $(n ! /(n-r) !=) 12$ permutations requiring $12+2$ weeks to execute. The temporal dimension of this experimental design poses an extra risk because it is difficult to 
execute repetitive tasks to the same level of quality. Fatigue and apathy among pupils and teachers would influence the results leading to unusable or missing data and possibly overall failure of the entire experiment. Consequently, we established a compromise where the lighting level is tested in two genuine $2 \times 2$ crossover periods: one period is with high ventilation rate in all rooms, the other with low ventilation rate in all rooms. Thus, by design, the experiment counter-acted the risk of air mixing between zones and suppressed the false positives from allowing the pupils to move to well-ventilated rooms during teamwork sessions.

This leads to an experimental design with a time span of 4 weeks plus 2 rehearsal weeks. Fig. 1 illustrates the intervention plan.

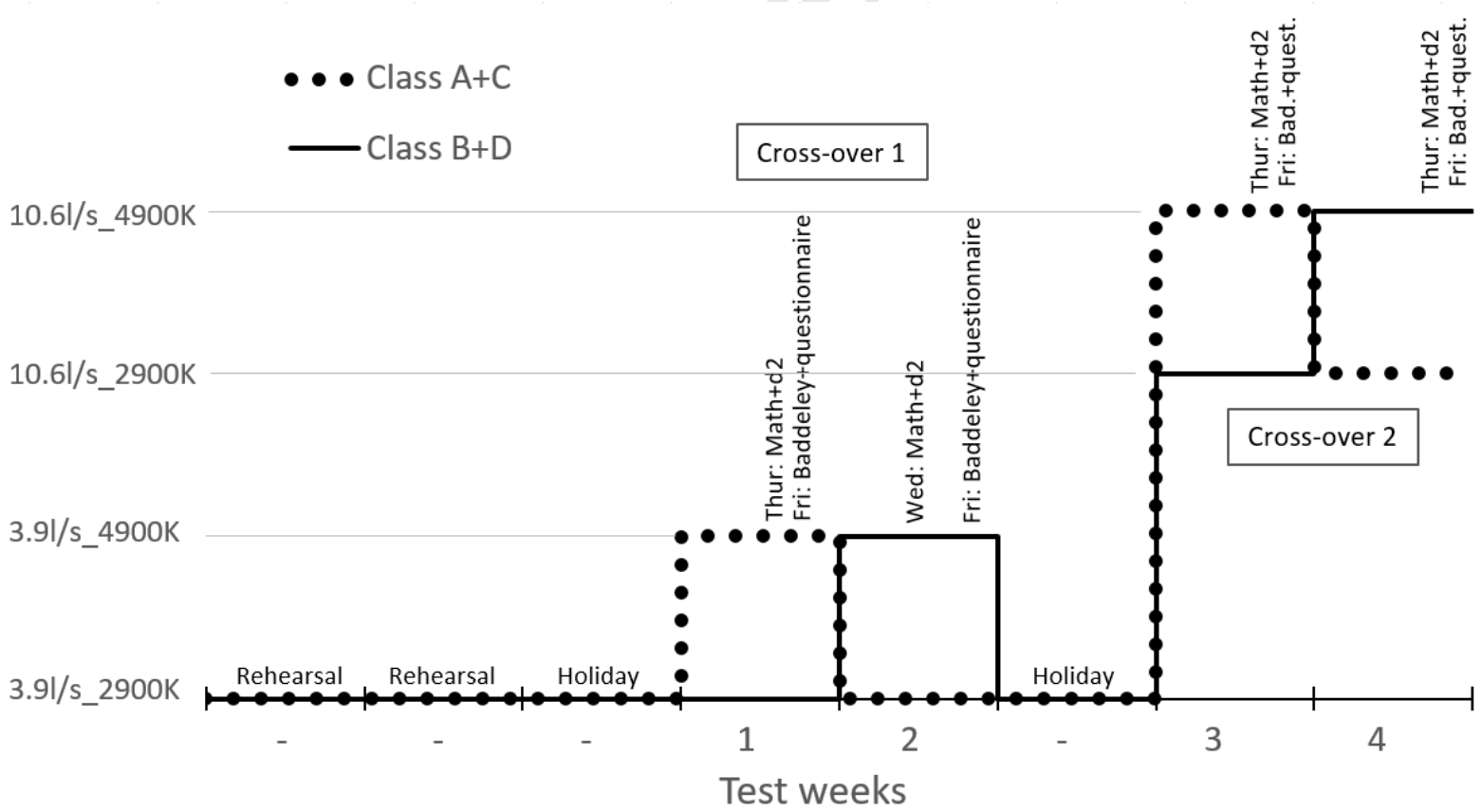

Fig. 1. Intervention plan with $2 x$ cross-over periods, test conditions and timing of tests. The tests are described in more detail in Section 4.1- 4.4. The classes are described in Section 3.

The effect of the external factors, like solar radiation and outdoor temperature, positive learning curve, fatigue, pupil-teacher relation and personal life of subjects, was minimized by taking special precautions: 
- The performance tests were executed in October and November when overcast skies and stable outdoor temperature of approx. $8-12^{\circ} \mathrm{C}$ are prevalent in a Danish climate. This also provided the best test conditions for the lighting system.

- The learning curve is positive because the performance of the pupils will increase over time caused by an increased familiarity with the performance tests [8]. The learning curve is theoretically S-shaped, meaning that the learning progression starts slowly, then accelerates and reaches a maximum over time. To ensure that pupils were completely familiarized with the tests, a rehearsal period was added prior to the actual experiment. Each test was rehearsed at least 8 times before the actual experiment began.

- Fatigue was fought by dividing the experiment into three periods, separated by two breaks, one of them coinciding with the autumn holiday week. The first period was the rehearsal weeks and subsequent periods the $2 \times 2$ crossover weeks. Also, to keep motivation high, a prize in the form of two pieces of candy were handed out to each pupil after the final test of the day. The motivation was also gauged every test week by adding motivational questions in the questionnaire, see Section 4.4.

- The effect of the pupil's personal life on the results was disclosed by adding two questions in the questionnaire (Section 4.4) regarding the overall well-being when in school and when outside school. Thus, it was then possible to filter for pupils that showed signs of distress due to personal issues.

\section{Field lab}

The school Byens Skole is from 1971 and located in the city of Valby close to Copenhagen, Denmark. The school comprises several buildings and educates children from preschool to $9^{\text {th }}$ grade, in total 10 grades. It is a private school which, in this context, means that approx. two-thirds of the tuition fee is subsidized 
by the local government. It means that the pupils are from homes with financial ressources above average, but also that some pupils have moved to the school because they were struggling in the public school sector. The school has approx. 455 pupils and a staff of 50 people. The field lab are four side-byside classrooms on the ground floor denoted Classroom A, B, C \& D. on Fig. 2. The classrooms were occupied by two classes of $4^{\text {th }}$ graders (class A \& B) and two classes of $5^{\text {th }}$ graders (class C \& D), in total 92 children, 44 girls and 48 boys aged $10-12$ years. To compensate for the age difference between $4^{\text {th }}$ and $5^{\text {th }}$ graders each test condition was concurrently applied in one class of $4^{\text {th }}$ graders and one class of $5^{\text {th }}$ graders. In this way the classes were grouped $A+C$ and $B+D$ and tested as detailed in Fig. 1, i.e. every pupil was tested under every test condition. To ensure sample sizes as big as possible, each test condition sample was constructed by merging the datasets from class $A+C$ with $B+D$.

The four side-by-side classrooms were particularly suited for an intervention study since they had the same dimensions and same window sizes with identical orientation towards South-East. The window dimensions and format are depicted on Fig. 2 and Fig. 3. The light transmittance of the 2-pane low-E glazing was estimated to be $82 \%$ and internal screens were manually operable. The users were strictly forbidden to open the windows during the tests and signs were placed over the window handles.

Several spot visits ensured that the occupants complied with the signs and it was only necessary to enforce the ban during the rehearsal weeks.

The school went through an extensive refurbishment prior to the performance experiments. The refurbishment introduced a 3-in-1 concept aereNmore ${ }^{1}$ specifically designed for classrooms and hallways. The concept is intended to simplify the process of refurbishing schools with mechanical balanced ventilation, LED-lighting panels as well as acoustic ceilings and wall absorbers. 


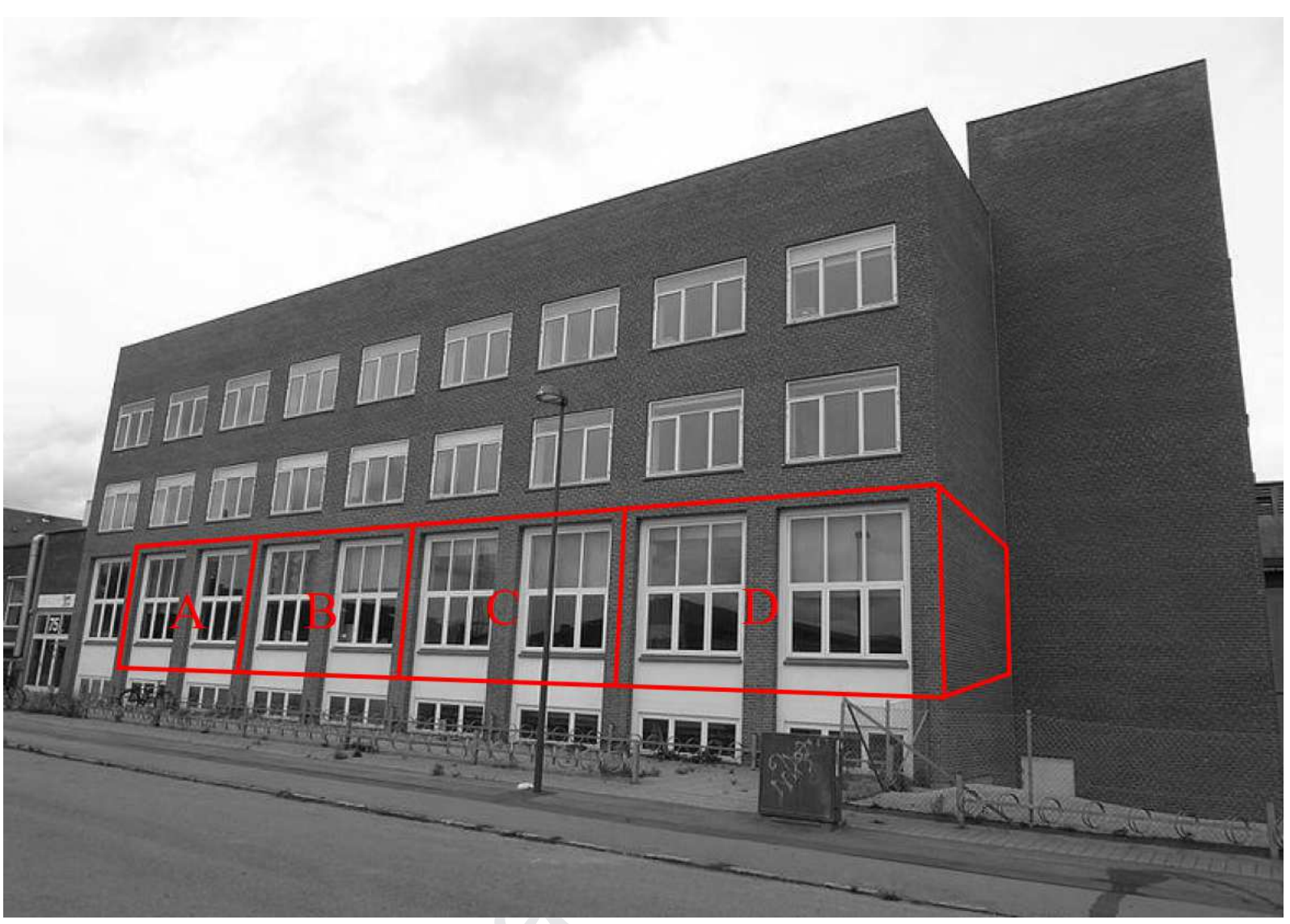

168

Fig. 2. School façade with location of the four classrooms in the field study

170

171

172

173 


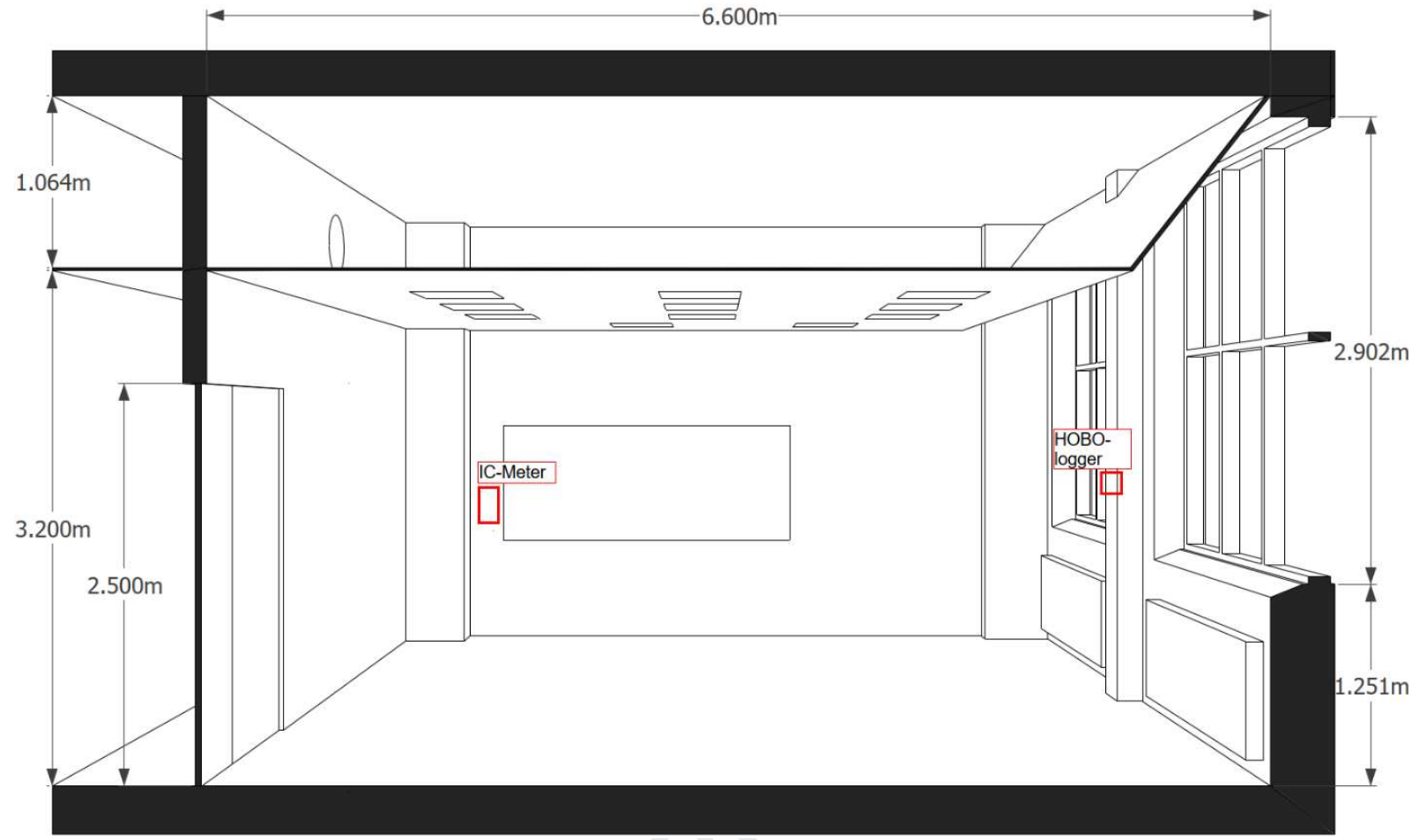

Fig. 3. Cross section of classroom

\subsection{Diffuse ventilation}

The ventilation air is provided by an air handling unit capable of supplying $6000 \mathrm{~m} 3 / \mathrm{h}$ in total to 6 classrooms and hallways. Each classroom is designed with a maximum supply ventilation rate of 900 m3/h. With approx. 23 pupils and one teacher in each classroom, this is enough to keep the CO2-level below $950 \mathrm{ppm}$. The inlet flow damper is controlled by a CO2-sensor in the extract and the extract damper operates as slave. The system balances the ventilation supply between classrooms and hallways to adjust for the whereabouts of the pupils. The ventilation is supplied in the void between the concrete slab and the suspended ceiling, in effect exploiting the void as a pressure chamber which distributes the ventilation air to the occupied zone through the perforations at very low velocity. This concept is often referred to in the literature as diffuse ventilation [22-25]. The ventilation supply temperature was set to 
$21^{\circ} \mathrm{C}$ during test weeks with high ventilation rate and $19^{\circ} \mathrm{C}$ during weeks with low ventilation rate to compensate for reduced cooling effect.

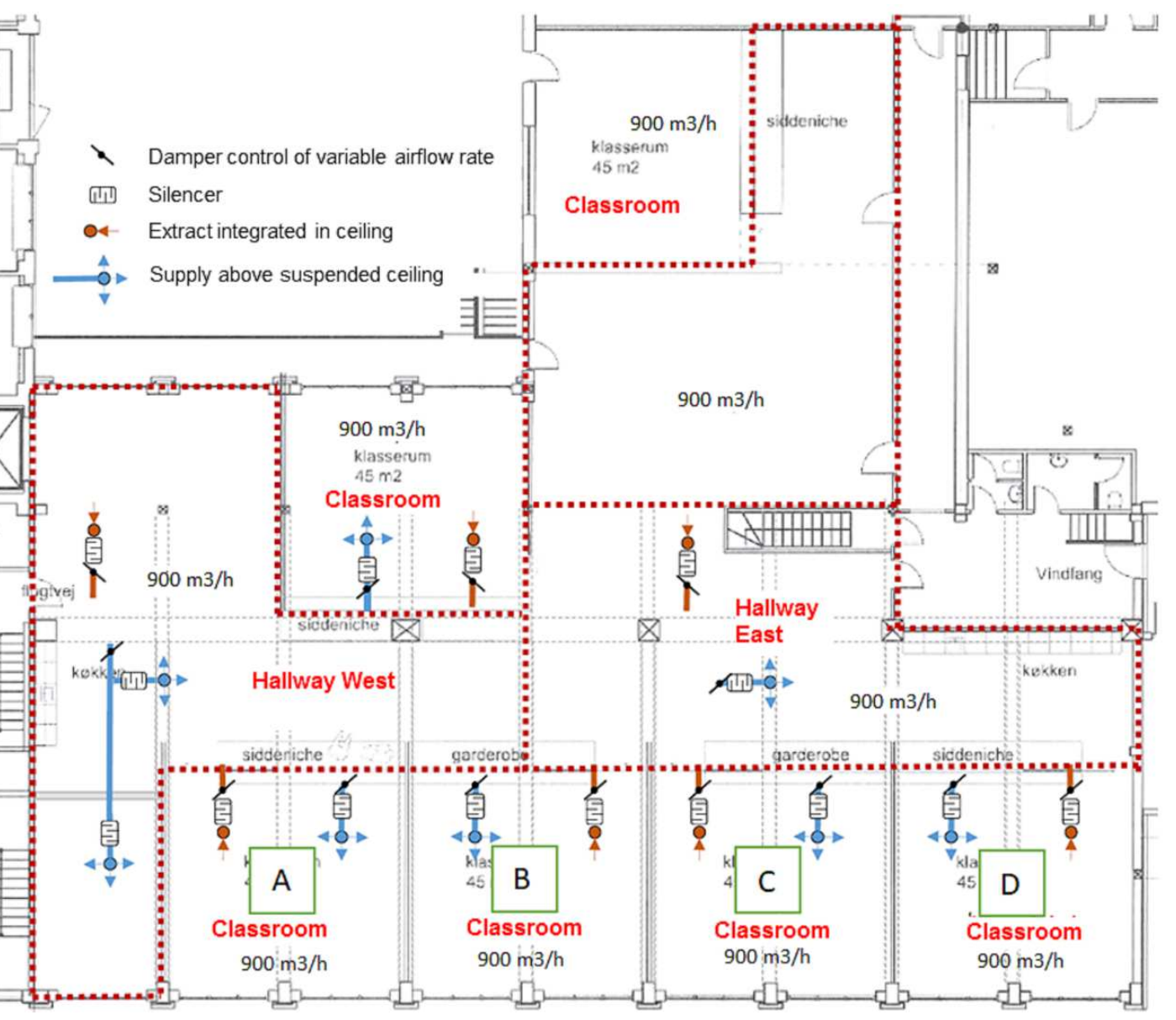

Fig. 4. Ventilation plan

\subsection{Dynamic lighting}

The lighting system in each classroom is made from 11 LED luminaires recessed in the ceiling suspension system, see Fig. 5. Through a control panel on the wall the users can choose between constant lighting 
scenario with a yellowish hue and dynamic lighting scenario with a bluish hue. The corresponding correlated colour temperatures and illuminances were measured with an ELMA 1336 chromameter to be $2900 \pm 89 \mathrm{~K}$ and $4900 \pm 149 \mathrm{~K}$. The resulting illuminances at the table height for constant and dynamic lighting mode are depicted on Fig. 6 . The average values at full power are $447 \pm 15$ lux and $748 \pm 24$ lux, respectively. In the dynamic lighting scenario, the luminaires adjust both colour temperature and luminance based on a preset schedule depicted on Fig. 7. However, in the hours prior to the testing time slot immediately before lunch, the colour temperature and illuminance level was constant. For both lighting scenarios the maintained illuminance $E_{m}$ of minimum 300 lux at work plane height is met [26]. The users are normally able to override the automatic settings, but this feature was disabled during the test weeks.
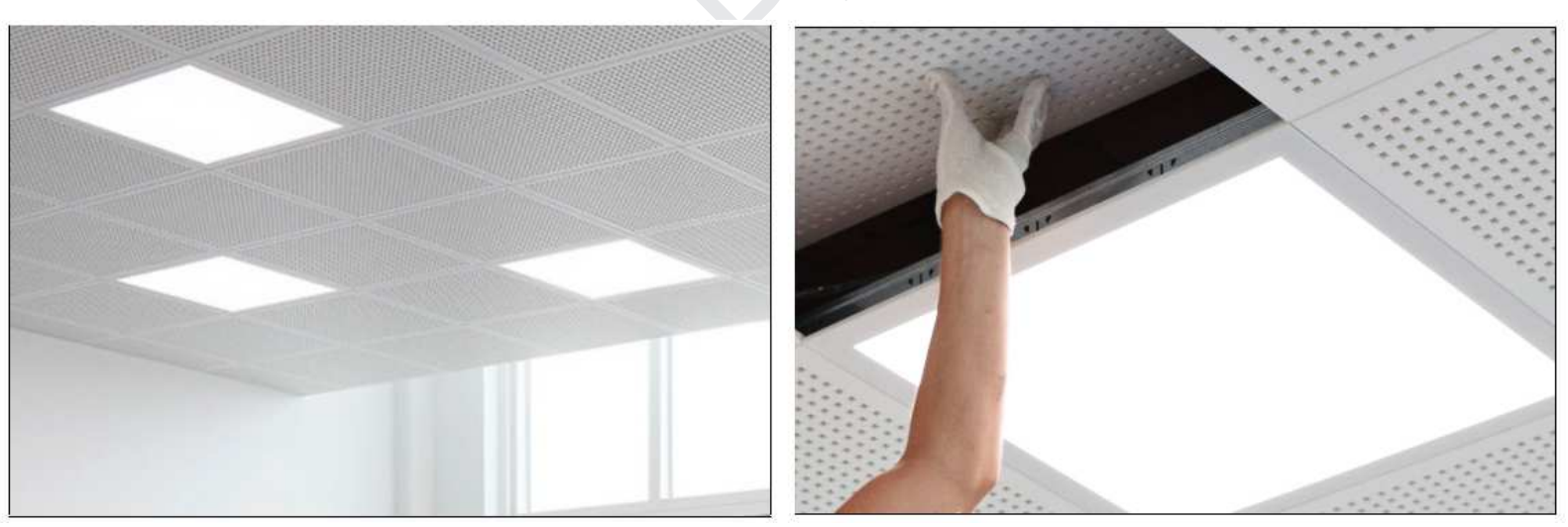

Fig. 5. Diffuse ventilation ceiling with luminaires 


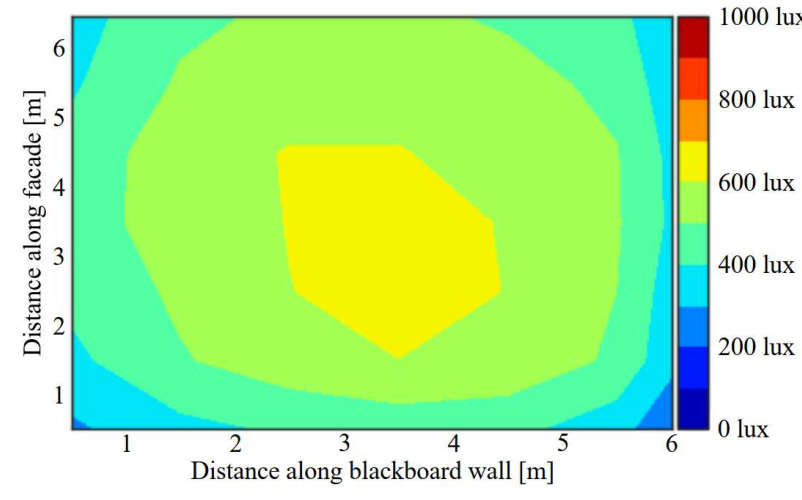

(a) Average: $447 \pm 15$ lux

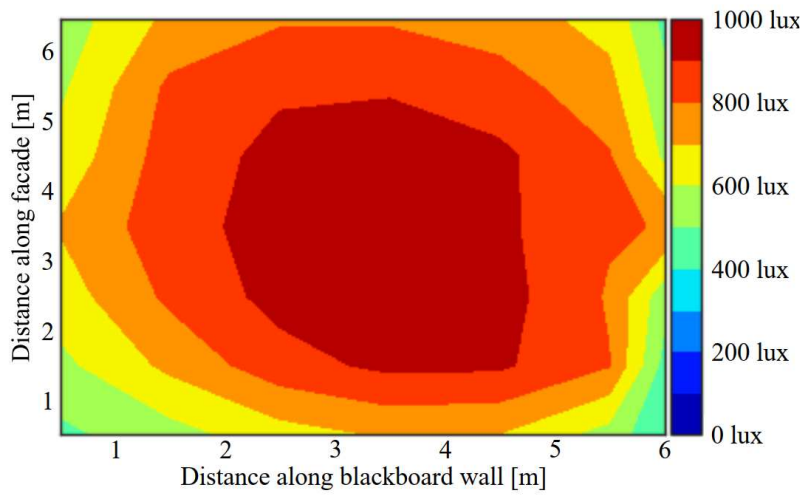

(b) Average: $748 \pm 24$ lux

Fig. 6. Contour map of the illuminance of the constant warm white (a), and the dynamic cool white light (b), corresponding to what was present during the tests between $11: 10$ and $11: 30$. There is approx. $67 \%$ higher illuminance in the classrooms with dynamic lighting compared to constant lighting.

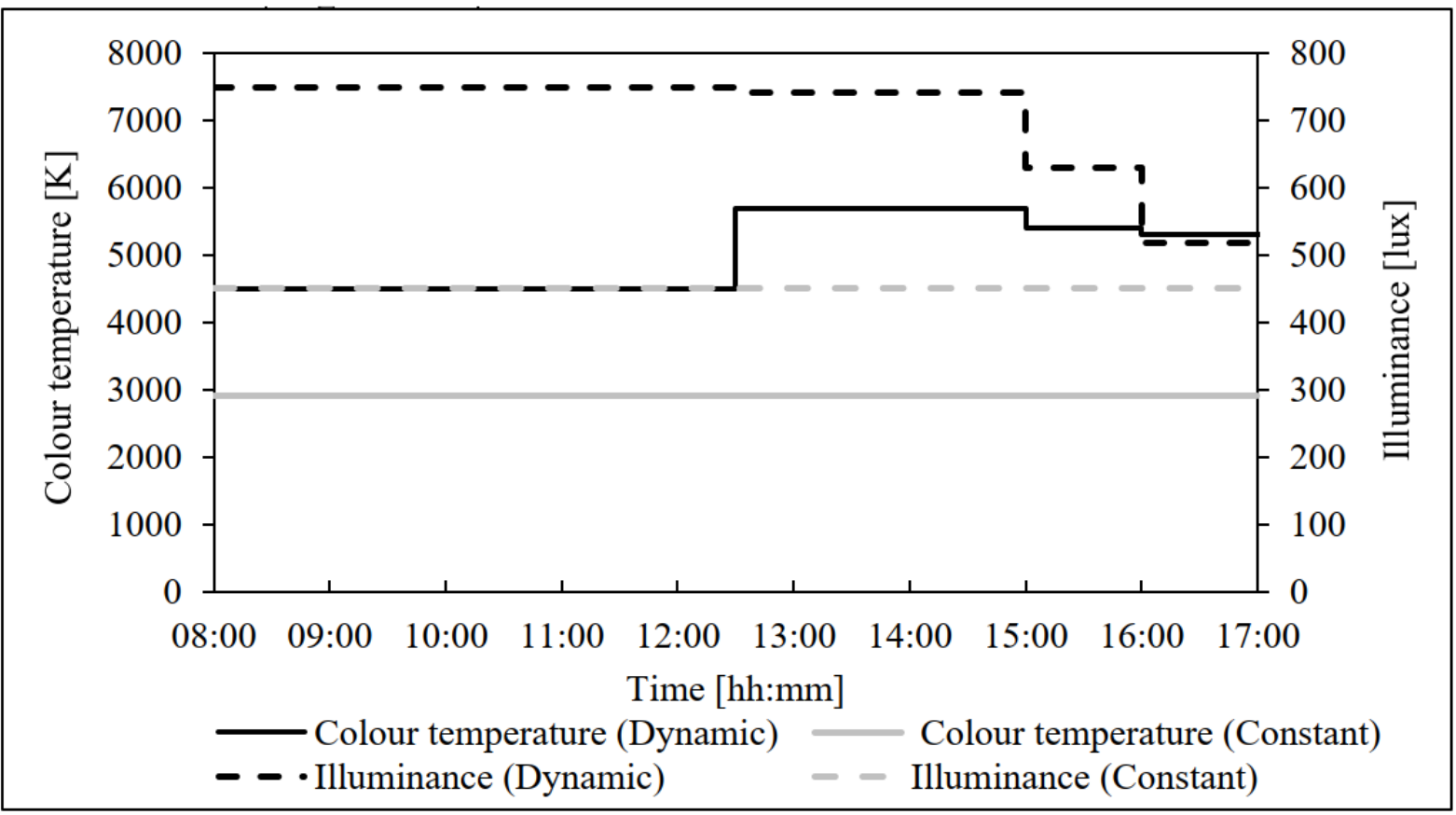




\subsection{Acoustics}

The acoustic ceiling and wall absorbers installed in each classroom create together the acoustic environment. The wall absorbers were mounted on the walls opposite the blackboard. The reverberation time $\mathrm{T}_{20}$ was measured according to ISO 3382-2 [27] without pupils but with furniture. The rounded result is 0.5 seconds in all classrooms $A, B, C, D$ hence fulfilling the Danish Building Code for classrooms which requires $T_{20}<0.6 \mathrm{~s}$. The acoustic performance was not changed during the performance experiments. Ambient noise levels were negligible.

\section{$3.4 \quad$ Equipment}

The indoor environment was closely monitored throughout the experiment weeks. The main parameters, $\mathrm{CO} 2$-concentration $( \pm 30 \mathrm{ppm})$, air temperature $\left( \pm 0.3^{\circ} \mathrm{C}\right)$, relative humidity $( \pm 2 \%)$ and noise levels (n/a) were measured with wireless IC-Meters [28]. Data was logged with 5 min interval and through a GSM connection the data was accessible and online. The IC-Meter unit was placed in each classroom in the corner furthest away from the door and the façade approx. $1 \mathrm{~m}$ from the wall. It was placed at a height of $1.20 \mathrm{~m}$ from the floor representing head height for a seated person. To capture uneven temperature distribution Hobo loggers model U12-012 from Onset were placed on the pillar between the windows and on the opposite wall at the height of $1.6 \mathrm{~m}$. The advertised accuracy of the air temperature measurements is $\pm 0.35^{\circ} \mathrm{C}$ from $0-50^{\circ} \mathrm{C}$. The IC-Meter and $\mathrm{HOBO}$ logger locations are depicted on Fig. 3.

\section{Measurements of performance}

Three tests were used to evaluate different cognitive processes imperative for the learning capability of school children. The tests were designed to assess cognitive performance in terms of attention, concentration, logical reasoning and math skills. During the rehearsal weeks the maximum number of 
assignments was adjusted to ensure that none of the children would be able to complete them all within the given time.

\section{1 d2-test}

The d2-test is a cancellation task, where the subjects are asked to mark targets and avoid so-called distractors. It evaluates the visual scanning speed of an individual and measures how well focus can be kept on a task [29]. It has been used previously in research into the processing speed of school children [30], attention of university students [31] as well as the effect of lighting on the concentration of pupils [18]. The test consists of 14 lines each containing 57 symbols. Each symbol is either a letter $d$ or a p with either one or two dots (' or ") above or below the letter as depicted on Fig. 8. The respondents were given 20 seconds per line to mark only the symbol $d$ with two dots (targets) while avoiding the other symbols (distractors). From the d2-test we deduct two metrics: TOT CORR is calculated as the amount of letters processed minus the amount of errors, i.e. the total sum of distractors incorrectly marked and number of d2-targets that have not been marked. CONC is the total number of correctly marked d2targets minus the total number of incorrectly marked distractors. TOT CORR and CONC are complimentary metrics of processing speed and concentration. The timing is very important in this test, as the subjects scan each of the 14 test lines for a fixed duration of time. In order to facilitate correct execution, short video clips with instructions and count-down timer were played-back during the test. The total duration of the test was approx. 5 minutes.

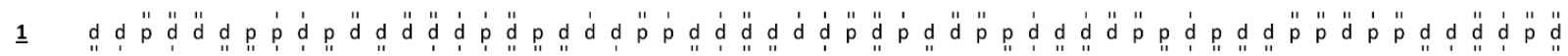

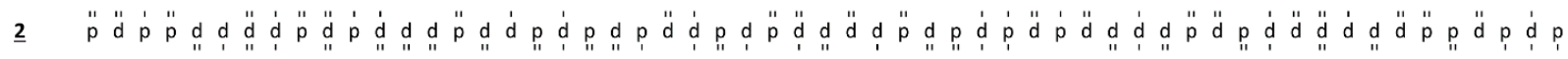

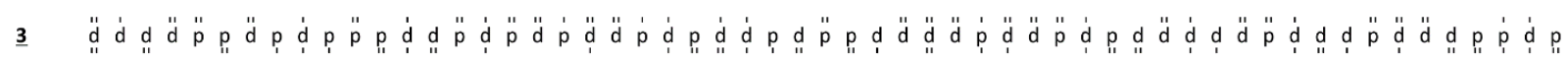

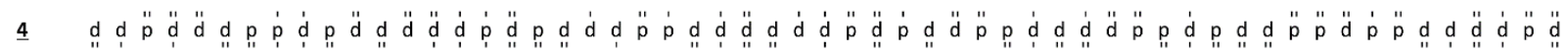




\subsection{Baddeley test}

In terms of logical reasoning, the Baddeley test is a short test that involves the understanding of sentences of various levels of syntactic complexity [32]. It gives a quick feedback on each individual's ability to think logically and sensible and has been used before to evaluate student performance before $[4,8]$. The test used in this study is a refinement of the original and is depicted on Fig. 9. It combines a statement with a geometric figure and requires the pupils to categorize the statement as True or False. Thus, the reasoning test combines both reading, comprehension and geometric aptitude. Two metrics were generated from the test: number of correctly marked and number of incorrectly marked answers. The test was eight min long.

The square is not within the circle

The triangle is smaller than the circle The circle is larger than the triangle

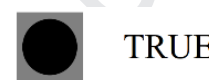

FALSE

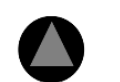

TRUE

FALSE

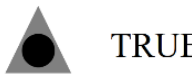

FALSE

Fig. 9. Short example of Baddeley test

\subsection{Math}

In the math test the pupils were asked to solve equations of multiplication and subtraction. The multiplication calculations were made as numbers between 2 and 5 multiplied by numbers between 10 and 50 . The subtraction problems were made as numbers between 10 and 40 subtracted from numbers between 50 and 80 . Two metrics, number of correct answers and number of erroneous answers were deducted. Plenty of equations were given to ensure that none of the children would be able to finish the test within the given eight minutes.

\subsection{Questionnaires}

A questionnaire was handed out after the Baddeley-test in every test week to determine the pupils' perception of the indoor environment. The questions were grouped into three overall parts. The first 
part was about the individual's overall well-being when in school and when outside school. This part was included to be able to identify and filter pupils with significant personal distress. The second part had eight questions about the perceived indoor environment in the classroom. These questions were about: Temperature, sensation of draught, air quality, noise and whether there was too much light or it was too dark in the room. The third part asked pupils to rate their motivation regarding headache, concentration difficulties, tiredness, work effort and well-being. A 5 point scale, illustrated as smileys, was used as assessment. It was only allowed to mark one smiley and if the mark was unclear or placed between two smileys it was not taken into account.

All tests and questionnaires were anonymized and given a unique ID-number before being further analyzed. The d2-test and math test were executed on Thursdays, and the Baddeley test and questionnaire on Fridays. Both days immediately before lunch and under the administration of the head teacher of the class. In test week 2 , the tests on Thursday were moved to Wednesday due to an excursion.

\subsection{Statistical analysis}

With the given experimental design with four test conditions, it is obvious to apply a 2x2 ANOVA analysis on the datasets to disclose the separate significance of ventilation and lighting on the pupil's performance plus interactions. However, during the experimental design we realized that sample size and data quality in a less-controlled field study environment were big risk factors. Consequently, we took a more solid approach and compared the indoor climate condition with low ventilation rate and constant lighting, which represents the "before refurbishment" situation or reference situation, to the condition with high ventilation rate and dynamic lighting, which represents the "after refurbishment" situation (scenario 5 in Table 1). Then, four other contrasting scenarios were constructed to uncover the effect of increasing the ventilation first, then followed by dynamic lighting and vice versa. These 
scenarios, we believe, aligns well with the decision process prior to a holistic refurbishment project where the order and funding of refurbishment measures is planned and prioritized.

The overall acceptable significance level is $\mathrm{P}<0.05$ (two-tailed), but when conducting several hypothesis tests, the family-wise error rate is increased. With a significance level of 0.05 , we may falsely reject the null hypothesis by chance 5 in 100, i.e., it will happen, but rarely. However, when we conduct multiple hypothesis tests with the same data, the risk of a rare event increases, and therefore the likelihood of incorrectly rejecting the null hypothesis. With five tests the chance of erroneously rejecting the null hypothesis at least once among the family of analyses (the family-wise error rate) amounts to $\alpha_{\mathrm{FW}}=1-(1-$ $0.05)^{5}=22.6 \%$. Consequently, we apply the Bonferroni correction to the overall significance level. With 5 hypothesis tests, this leads to a new acceptable significance level across all comparisons of $0.05 / 5=$ 0.01 .

When two test conditions are compared, the Shapiro-Wilk's test was run on each dataset to test for normality. When both datasets were normally distributed, the paired Student's t-test was applied, otherwise the Wilcoxon matched-pair signed-rank test was used. We used the open-source software tool RStudio (2019).

\subsection{Filtration of responses}

Before each hypothesis testing the datasets were filtered for responses that did not exist in both datasets, i.e. only complete within-subject responses are included. The major cause of this was pupils being absent due to sickness or leave. The questionnaire did not disclose any reasons why some pupils should be excluded due to personal distress or bad relations.

In the final test week, Class D made the Baddeley test and the questionnaire without their usual head teacher and instead with a temporary teacher. The pupils expressed afterwards that the class had been with many distractions. In addition, the analysis showed highly divergent results from the previous 
weeks. Consequently, the Baddeley test data from class D in week 4 was discarded all together. The questionnaire data was not discarded.

\section{Results}

The results are presented in the following paragraphs. The physical conditions, temperature and CO2concentration during the experiment is presented first. Then follows the results of the statistical hypothesis testing of ventilation and lighting interventions separately, and lastly the combined effects of both interventions.

\subsection{Indoor environment conditions}

Table 2 summarizes the indoor environment conditions during the test experiments. The physical values are measured with IC-Meters, except the façade temperature and the outdoor temperature which were logged by HOBO loggers, see Fig. 3. The summary includes weekly values averaged over the occupied hours, and the indoor conditions specific to the performance testing periods. The ventilation flow rate was controlled by VAV dampers from $\mathrm{CO}_{2}$-sensors. Assuming perfect mixing, the low and high mean ventilation flow rate was found through $\mathrm{CO}_{2}$-decay method to be approx. 3.9 and $10.6 \mathrm{l} / \mathrm{s}$ per person, respectively. These values align with the ventilation system design values of $180-900 \mathrm{~m} 3 / \mathrm{h}$ per classroom and 22 persons present on a daily basis ( 2.3 and $11.4 \mathrm{l} / \mathrm{s}$ per person).

It was important during the four performance testing weeks to keep the other indoor physical conditions constant. As summarized in Table 2, the mean weekly CO2-concentration in low ventilation conditions was 1148 ppm, peaking at 1860 during tests and 753 ppm in high ventilation conditions, peaking at $966 \mathrm{ppm}$. The outdoor temperature was approx. $13^{\circ} \mathrm{C}$, dropping to $7^{\circ} \mathrm{C}$ and the indoor temperature was within comfort with a weekly mean of $23^{\circ} \mathrm{C}$, dropping as low as $21.3^{\circ} \mathrm{C}$ and peaking as high as $25.6^{\circ} \mathrm{C}$ during some tests. On average the temperature during tests was approx. $24^{\circ} \mathrm{C}$ in low ventilation weeks and $23^{\circ} \mathrm{C}$ in high ventilation weeks. 
The temperature at the façade was slightly colder, but not significantly. Weekly mean relative humidity was also well within comfort range at $30-46 \%$. In this moderate environment, the effect of relative humidity on operative temperature is very modest and on par with the accuracy of the temperature measuring equipment and therefore deemed negligible.

\subsection{Performance tests}

The results of the statistical hypothesis testing are reported in Table 3, Table 4, Table 5, Table 6 and

Table 7. The five tables report the statistics from the scenario comparisons that were listed in Table 1 in order to disclose the effect of individual measures as well as the combined effects. Significant effects after application of the Bonferroni correction are highlighted in bold. An overview of the most noteworthy combined effects is conveyed by the illustrations in Fig. 10, Fig. 11 and Fig. 12.

Most of the performance metrics show improvement when changing to higher ventilation rate and/or changing to dynamic cool lighting. In some instances, the error metrics show decreased performance but these numbers are calculated from very small sample sizes: the total number of errors was quite small compared to the number of correctly executed tests and in most instances the mean value shifts just 1 or 2 to either positive or negative side. Consequently, we put less emphasis on the error metrics, positive or negative. 
Table 2 Indoor climate in the classrooms during the test weeks and during the performance tests.

\begin{tabular}{|c|c|c|c|c|c|c|c|c|c|c|c|c|c|c|c|c|}
\hline \multirow[b]{3}{*}{ Class room } & \multicolumn{4}{|c|}{ Week 1} & \multicolumn{4}{|c|}{ Week 2} & \multicolumn{4}{|c|}{ Week 3} & \multicolumn{4}{|c|}{ Week 4} \\
\hline & \multicolumn{2}{|c|}{$3.9 \mathrm{l} / \mathrm{s} \_4900 \mathrm{~K}$} & \multicolumn{2}{|c|}{ 3.9l/s_2900K } & \multicolumn{2}{|c|}{ 3.9l/s_2900K } & \multicolumn{2}{|c|}{ 3.9l/s_4900K } & \multicolumn{2}{|c|}{$10.6 \mathrm{l} / \mathrm{s} \_4900 \mathrm{~K}$} & \multicolumn{2}{|c|}{$10.6 \mathrm{l} / \mathrm{s} \_2900 \mathrm{~K}$} & \multicolumn{2}{|c|}{$10.6 \mathrm{l} / \mathrm{s} \_2900 \mathrm{~K}$} & \multicolumn{2}{|c|}{$10.6 \mathrm{l} / \mathrm{s} \_4900 \mathrm{~K}$} \\
\hline & A & C & B & $\mathrm{D}$ & A & C & B & $\mathrm{D}$ & $A$ & C & B & $\mathrm{D}$ & $A$ & C & B & D \\
\hline \multicolumn{17}{|c|}{ Weekly occupied conditions } \\
\hline CO2-concentration, & 1175 & 1212 & 1119 & 1166 & 1094 & 1136 & 1123 & 1159 & 784 & 777 & 762 & 707 & 797 & 725 & 730 & 739 \\
\hline mean \pm SD $[p p m]$ & \pm 292 & \pm 357 & \pm 323 & \pm 298 & \pm 319 & \pm 358 & \pm 325 & \pm 296 & \pm 136 & \pm 179 & \pm 114 & \pm 174 & \pm 155 & \pm 125 & \pm 102 & \pm 68 \\
\hline Air temperature, & 24.3 & 24.3 & 24.0 & 23.0 & 23.5 & 23.7 & 23.0 & 21.2 & 23.2 & 23.1 & 23.1 & 22.5 & 22.4 & 22.6 & 22.3 & 22.0 \\
\hline mean $\pm \mathrm{SD}\left[{ }^{\circ} \mathrm{C}\right]$ & \pm 0.8 & \pm 0.9 & \pm 0.8 & \pm 0.5 & \pm 1.3 & \pm 1.7 & \pm 1.0 & \pm 0.8 & \pm 0.9 & \pm 0.9 & \pm 0.7 & \pm 0.7 & \pm 0.7 & \pm 1.0 & \pm 0.7 & \pm 0.6 \\
\hline Air temp. at façade ${ }^{\dagger}$ & 22.1 & 21.9 & 21.9 & 21.7 & 20.8 & 20.7 & 20.3 & 19.8 & 20.7 & 20.5 & 20.7 & 21.5 & 19.9 & 19.5 & 19.7 & 21.0 \\
\hline mean $\pm \mathrm{SD}\left[{ }^{\circ} \mathrm{C}\right]$ & \pm 1.3 & \pm 1.4 & \pm 1.5 & \pm 1.5 & \pm 1.4 & \pm 1.4 & \pm 1.5 & \pm 1.5 & \pm 1.4 & \pm 1.4 & \pm 1.5 & \pm 1.5 & \pm 1.3 & \pm 1.4 & \pm 1.5 & \pm 1.5 \\
\hline Relative humidity, & 40 & 40 & 39 & 42 & 41 & 41 & 42 & 46 & 42 & 43 & 42 & 43 & 30 & 30 & 30 & 32 \\
\hline mean \pm SD [\%] & \pm 4 & \pm 5 & \pm 5 & \pm 4 & \pm 4 & \pm 5 & \pm 5 & \pm 4 & \pm 4 & \pm 4 & \pm 4 & \pm 4 & \pm 2 & \pm 2 & \pm 2 & \pm 2 \\
\hline Outdoor temperature, & 13.4 & 14.0 & 13.3 & 12.5 & 12.5 & 12.9 & 12.4 & 11.8 & 12.2 & 12.3 & 12.1 & 12.0 & 7.9 & 7.2 & 7.2 & 6.9 \\
\hline mean $\pm \mathrm{SD}\left[{ }^{\circ} \mathrm{C}\right]$ & \pm 5.3 & \pm 6.2 & \pm 6.3 & \pm 5.3 & \pm 5.0 & \pm 5.6 & \pm 5.3 & \pm 4.3 & \pm 3.5 & \pm 3.4 & \pm 3.4 & \pm 3.8 & \pm 4.1 & \pm 3.0 & \pm 3.0 & \pm 2.9 \\
\hline \multicolumn{17}{|c|}{ Conditions during d2 \& math } \\
\hline CO2-concentration, & 1525 & 1639 & 1598 & 1648 & 1173 & 1619 & 1513 & 1443 & 840 & 911 & 845 & 720 & 795 & 905 & 830 & 808 \\
\hline $\min -\max [p p m]$ & 1630 & 1860 & 1704 & 1781 & 1608 & 1821 & 1623 & 1537 & 893 & 966 & 928 & 777 & 930 & 941 & 901 & 900 \\
\hline Air temperature, & 25.1 & 25.1 & 24.6 & 23.7 & 23.8 & 24.1 & 23.6 & 21.3 & 23.5 & 23.9 & 23.8 & 23.0 & 22.3 & 23.0 & 22.5 & 21.8 \\
\hline $\min -\max \left[{ }^{\circ} \mathrm{C}\right]$ & 25.6 & 25.2 & 24.9 & 24.0 & 24.5 & 24.7 & 23.9 & 21.5 & 23.9 & 24.1 & 23.8 & 23.0 & 22.7 & 23.1 & 22.7 & 21.9 \\
\hline Number of persons & 22 & 24 & 23 & 21 & 22 & 23 & 22 & 22 & 23 & 22 & 24 & 20 & 23 & 22 & 23 & 21 \\
\hline Vent. rate* $[\mathrm{l} / \mathrm{s} /$ pers $]$ & 4.0 & 3.5 & 3.7 & 3.6 & 4.7 & 3.5 & 4.0 & 4.3 & 10.1 & 8.6 & 9.5 & 13.5 & 10.6 & 8.9 & 10.1 & 10.4 \\
\hline \multicolumn{17}{|c|}{ Conditions during Baddeley \& questionnaires } \\
\hline CO2-concentration, & 1508 & 1582 & 1499 & 1394 & 1564 & 1469 & 1556 & 1404 & 779 & 847 & 768 & 718 & 846 & 827 & 751 & 734 \\
\hline $\min -\max [\mathrm{ppm}]$ & 1753 & 1807 & 1653 & 1660 & 1724 & 1685 & 1735 & 1666 & 918 & 923 & 856 & 836 & 926 & 878 & 833 & 815 \\
\hline Air temperature, & 24.9 & 24.0 & 24.1 & 22.6 & 24.6 & 24.1 & 23.9 & 21.9 & 24.0 & 23.9 & 24.0 & 23.1 & 22.0 & 22.1 & 21.8 & 21.5 \\
\hline $\min -\max \left[{ }^{\circ} \mathrm{C}\right]$ & 25.1 & 24.6 & 24.2 & 23.2 & 25.1 & 24.5 & 24.3 & 22.0 & 24.7 & 24.3 & 24.1 & 23.2 & 22.4 & 22.4 & 21.9 & 21.7 \\
\hline Number of persons & 22 & 23 & 23 & 22 & 23 & 20 & 22 & 22 & 22 & 22 & 23 & 21 & 24 & 20 & 20 & 21 \\
\hline Vent. rate* $[\mathrm{l} / \mathrm{s} /$ pers $]$ & 3.8 & 3.6 & 4.1 & 4.1 & 3.8 & 4.0 & 3.7 & 4.2 & 10.7 & 9.7 & 11.4 & 12.3 & 9.5 & 10.3 & 12.2 & 12.3 \\
\hline
\end{tabular}




\subsubsection{Lighting}

The true crossover design included changing the lighting conditions at first low and then at high ventilation rate. This is reported in Table 3 and Table 4. At low ventilation rate, the math test improved significantly $(12.1 \%, \mathrm{P}=0.009)$ with smaller non-significant improvements in the d2-test when dynamic cool lighting was provided (Table 3). Then, when dynamic lighting was combined with high ventilation rate, the d2-test improved significantly with TOT CORR 5.4\% $(P=0.003)$ and CONC 6.1\% $(P=0.002)($ Table 4). Math also improved (5.7\%) but without significance. The results indicate that the cognitive processes involved in the $\mathrm{d} 2$-test is boosted by the combination of high ventilation rate and dynamic cool lighting conditions, whereas math skills benefit from changing to dynamic lighting $(12.1 \%, P=0.009)$ at low ventilation rates and less for higher ventilation rates $(5.7 \%, \mathrm{P}=0.147)$, which suggests that initial improvements from a reference situation have the biggest impact and subsequent changes a smaller impact on math skills. The significant impact of dynamic lighting on the "before" situation concurs with the claims of the producer of the LED-panels, who names the dynamic cool lighting condition "math" light. These results supplement Mott et al. [7] who found that $3^{\text {rd }}$ graders oral reading fluency improved $36 \%$ when given 1000 lux at $6500 \mathrm{~K}$ instead of 500 lux at $3500 \mathrm{~K}$ but found no influence on motivation or concentration.

\subsubsection{Ventilation}

The effect of higher ventilation rate at different lighting conditions is reported in Table 5 and Table 6. The ventilation rate was increased from $3.9 \mathrm{l} / \mathrm{s}$ to $10.6 \mathrm{l} / \mathrm{s}$ per person on average, illustrated by a CO2concentration reduction from approx. 1600 ppm to 900 ppm (Table 2). While showing overall positive performance changes in all tests with negligible effect on the error rates, only the d2 metrics show significant improvement but only when given both high ventilation rate and dynamic lighting $(\Delta>+5.0 \%$, $P<0.003)$. Indeed, providing higher ventilation rate to the pupils seems to have had a smaller effect on 
their performance than anticipated based on results in the literature. Wargocki and Wyon [33] found that doubling the outdoor air supply rate increased the execution speed of school-work related tasks by $8 \%$ overall, and $14 \%$ in the most significantly affected tasks. Similarly in 2016, Petersen et al. [4] found statistically significant performance increases for different schoolwork tasks of $3.2 \%$ to $7.4 \%$ when increasing the ventilation rate from 1.7 to $6.6 \mathrm{l} / \mathrm{s}$ per person. The results reported in Table 5 and Table 6 support that the d2-metrics are boosted by combining indoor environment improvements. The math results - though non-significant - benefit more from higher ventilation rates at warm constant lighting conditions $(6.1 \%, \mathrm{P}=0.108)$ than at dynamic cool lighting conditions $(2.7 \%, \mathrm{P}=0.539)$, which suggests some canceling effect between improvements.

In Table 7 the combined effect of providing higher ventilation rate and dynamic lighting conditions is reported. Both d2-tests and math tests were significantly impacted from the combination. The metrics TOT CORR and CONC showed improvements of $6.6 \%$ and $8.3 \%(P=<0.001)$ and the math test showed $11.8 \%(P=0.006)$.

The Baddeley performance metrics (Correct answers and Errors) did not show any significance in any of the scenarios and the scores point in both positive, neutral, and negative direction. Thus, we disregard the Baddeley test results all together. 
410 Scenario 1: performance by children when lighting changes from constant warm to dynamic cool at low ventilation rate

\begin{tabular}{|c|c|c|c|c|c|c|c|}
\hline $\begin{array}{l}\text { Performance } \\
\text { test }\end{array}$ & $\begin{array}{l}\text { Sample size } \\
\mathrm{n}\left(\mathrm{n}_{\mathrm{A}}+\mathrm{n}_{\mathrm{B}}+\mathrm{n}_{\mathrm{C}}+\mathrm{n}_{\mathrm{D}}\right)\end{array}$ & $\begin{array}{l}\text { Performance } \\
\text { metric }\end{array}$ & $\begin{array}{r}3.9 \mathrm{l} / \mathrm{s} \_2900 \mathrm{~K} \\
\text { mean } \pm \text { SD (median) }\end{array}$ & $\begin{array}{r}3.9 \mathrm{l} / \mathrm{s} \_4900 \mathrm{~K} \\
\text { mean } \pm \mathrm{SD}(\text { median) }\end{array}$ & $\begin{array}{l}\text { Performance } \\
\text { changet, \% }\end{array}$ & $\begin{array}{l}\text { Statistical } \\
\text { test }\end{array}$ & P-value \\
\hline$d 2$ & $82(19+21+22+20)$ & TOT CORR & $366 \pm 79(375)$ & $372 \pm 69(380)$ & 1.6 & t-test & 0.185 \\
\hline \multirow[t]{2}{*}{ Baddeley } & $79(20+21+18+20)$ & Correct answers & $37 \pm 15(36)$ & $35 \pm 16(35)$ & -5.4 & Wilcoxon & 0.265 \\
\hline & & Errors & $5 \pm 7(2)$ & $6 \pm 10(2)$ & -20.0 & Wilcoxon & 0.93 \\
\hline Math & $80(19+21+21+19)$ & Correct answers & $33 \pm 18(32)$ & $37 \pm 19$ (38) & 12.1 & Wilcoxon & $0.009 * *$ \\
\hline
\end{tabular}

411 Note: Asterisks emphasize the significance: P-value $\leq 0.05\left({ }^{*}\right), \leq 0.01\left({ }^{* *}\right)$ and P-value $\leq 0.001\left({ }^{* * *}\right)$.

412 The term "change" refers to the relative change in the mean values between the scenarios. Positive values denote a performance increase, negative a

413 decrease.

Table 4

417 Scenario 2: performance by children when lighting changes from constant warm to dynamic cool at high ventilation rate

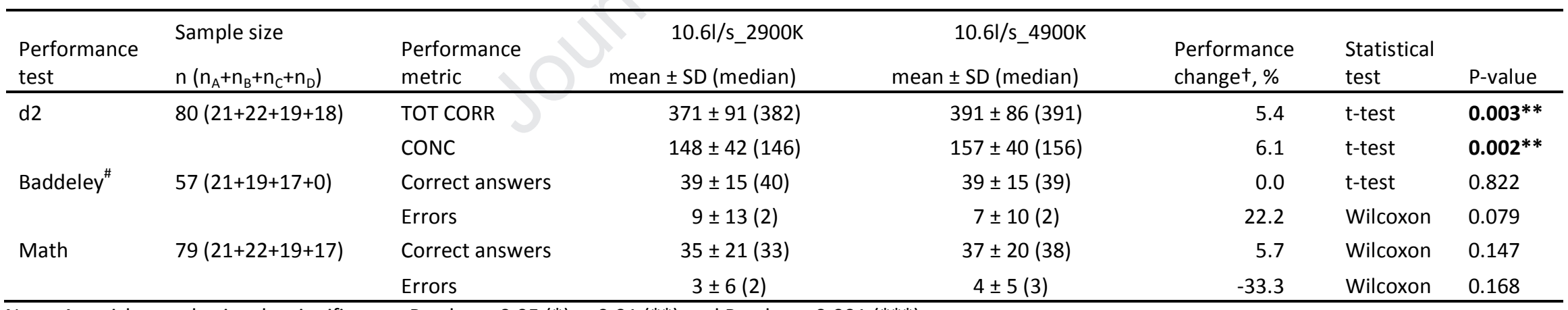

418 Note: Asterisks emphasize the significance: P-value $\leq 0.05(*), \leq 0.01\left({ }^{* *}\right)$ and P-value $\leq 0.001\left({ }^{* * *}\right)$.

419 "The results from class $D$ in test week 4 are not included due to badly executed Baddeley test by temporary teacher.

420 The term "change" refers to the relative change in the mean values between the scenarios. Positive values denote a performance increase, negative a

421 decrease. 
424 Scenario 3: performance by children when ventilation rate changes from low to high in constant warm lighting conditions

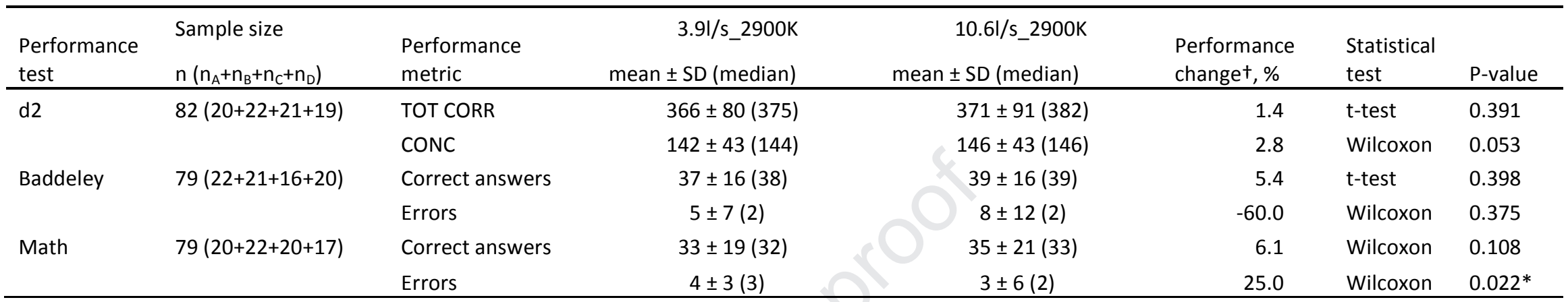

425 Note: Asterisks emphasize the significance: P-value $\leq 0.05\left({ }^{*}\right), \leq 0.01\left({ }^{* *}\right)$ and P-value $\leq 0.001(* * *)$

426 The term "change" refers to the relative change in the mean values between the scenarios. Positive values denote a performance increase, negative a

427 decrease.

Table 6

430 Scenario 4: performance by children when ventilation rate changes from low to high in dynamic cool lighting conditions

\begin{tabular}{|c|c|c|c|c|c|c|c|}
\hline $\begin{array}{l}\text { Performance } \\
\text { test }\end{array}$ & $\begin{array}{l}\text { Sample size } \\
\mathrm{n}\left(\mathrm{n}_{\mathrm{A}}+\mathrm{n}_{\mathrm{B}}+\mathrm{n}_{\mathrm{C}}+\mathrm{n}_{\mathrm{D}}\right)\end{array}$ & $\begin{array}{l}\text { Performance } \\
\text { metric }\end{array}$ & $\begin{array}{l}\text { Scenario 3.9l/s_4900K } \\
\text { mean } \pm \text { SD (median) }\end{array}$ & $\begin{array}{l}\text { Scenario } 10.6 \mathrm{l} / \mathrm{s} \_4900 \mathrm{~K} \\
\text { mean } \pm \text { SD (median) }\end{array}$ & $\begin{array}{l}\text { Performance } \\
\text { change } \dagger, \%\end{array}$ & $\begin{array}{l}\text { Statistical } \\
\text { test }\end{array}$ & P-value \\
\hline \multirow[t]{2}{*}{$d 2$} & $81(20+21+21+19)$ & TOT CORR & $374 \pm 66(380)$ & $393 \pm 83(396)$ & 5.1 & t-test & $0.003 * *$ \\
\hline & & CONC & $149 \pm 32(152)$ & $158 \pm 39(158)$ & 6.0 & t-test & $<0.001 * * *$ \\
\hline \multirow[t]{2}{*}{ Baddeley" } & $57(19+19+19+0)$ & Correct answers & $38 \pm 16(40)$ & $39 \pm 15$ (39) & 2.6 & t-test & 0.76 \\
\hline & & Errors & $7 \pm 11(2)$ & $6 \pm 10(2)$ & 14.3 & Wilcoxon & 0.474 \\
\hline \multirow[t]{2}{*}{ Math } & $81(20+21+21+19)$ & Correct answers & $37 \pm 19$ (39) & $38 \pm 20$ (39) & 2.7 & Wilcoxon & 0.539 \\
\hline & & Errors & $4 \pm 4(2)$ & $4 \pm 5(3)$ & 0.0 & Wilcoxon & 0.342 \\
\hline
\end{tabular}

Note: Asterisks emphasize the significance: P-value $\leq 0.05\left({ }^{*}\right), \leq 0.01\left({ }^{* *}\right)$ and P-value $\leq 0.001\left({ }^{* *}\right)$.

432 "The results from class $D$ in test week 4 are not included due to badly executed Baddeley test by temporary teacher.

433 The term "change" refers to the relative change in the mean values between the scenarios. Positive values denote a performance increase, negative a

434 decrease. 


\section{Table 7}

438 Scenario 5: performance by children when ventilation rate changes from low to high and lighting conditions changes from constant warm to dynamic cool

\begin{tabular}{|c|c|c|c|c|c|c|c|}
\hline $\begin{array}{l}\text { Performance } \\
\text { test }\end{array}$ & $\begin{array}{l}\text { Sample size } \\
\mathrm{n}\left(\mathrm{n}_{\mathrm{A}}+\mathrm{n}_{\mathrm{B}}+\mathrm{n}_{\mathrm{C}}+\mathrm{n}_{\mathrm{D}}\right)\end{array}$ & $\begin{array}{l}\text { Performance } \\
\text { metric }\end{array}$ & $\begin{array}{l}\text { Scenario 3.9l/s_2900K } \\
\text { mean } \pm \text { SD (median) }\end{array}$ & $\begin{array}{l}\text { Scenario } 10.6 \mathrm{I} / \mathrm{s} \_4900 \mathrm{~K} \\
\text { mean } \pm \text { SD (median) }\end{array}$ & $\begin{array}{l}\text { Performance } \\
\text { change } \dagger, \%\end{array}$ & $\begin{array}{l}\text { Statistical } \\
\text { test }\end{array}$ & P-value \\
\hline \multirow[t]{2}{*}{ d2 } & $81(20+22+20+19)$ & TOT CORR & $366 \pm 77(375)$ & $390 \pm 86$ (396) & 6.6 & t-test & $<0.001 * * *$ \\
\hline & & CONC & $145 \pm 39(145)$ & $157 \pm 40(158)$ & 8.3 & Wilcoxon & $<0.001 * * *$ \\
\hline \multirow[t]{2}{*}{ Baddeley } & $56(20+19+17+0)$ & Correct answers & $37 \pm 16(38)$ & $39 \pm 15$ (39) & 5.4 & t-test & 0.49 \\
\hline & & Errors & $5 \pm 8(2)$ & $6 \pm 10(2)$ & -20.0 & Wilcoxon & 0.932 \\
\hline \multirow[t]{2}{*}{ Math } & $80(20+22+20+18)$ & Correct answers & $34 \pm 19(32)$ & $38 \pm 20$ (39) & 11.8 & Wilcoxon & $0.006 * *$ \\
\hline & & Errors & $4 \pm 3(3)$ & $4 \pm 5(3)$ & 0.0 & Wilcoxon & 0.984 \\
\hline
\end{tabular}

439 Note: Asterisks emphasize the significance: P-value $\leq 0.05\left({ }^{*}\right), \leq 0.01\left({ }^{* *}\right)$ and P-value $\leq 0.001(* * *)$.

$440 \quad$ \#The results from class $D$ in test week 4 are not included due to badly executed Baddeley test by temporary teacher.

441 The term "change" refers to the relative change in the mean values between the scenarios. Positive values denote a performance increase, negative a

442 decrease. 


\subsubsection{Combined effect of ventilation and lighting}

The most noteworthy performance changes from Table 3-Table 7 are put into the graphs in Fig. 10 (TOT CORR), Fig. 11 (CONC) and Fig. 12 (Math). The graphs show the combined effect of higher ventilation rate and dynamic lighting with high statistical significance (dashed horizontal line). For the metrics TOT CORR (Fig. 10) and CONC (Fig. 11) the total performance increase coincides very closely to the added effect of introducing first one improvement, then another. The P-values are included to indicate the trustworthiness of each individual measure.

The graphs show that the cognitive processes involved in the d2-test is boosted by the combination of high ventilation rate and dynamic cool lighting conditions irrespective of the initial measure. The math results (Fig. 12) show 50-50 attribution when ventilation is applied first whereas dynamic lighting as a first measure seems to have a big stand-alone effect making any subsequent improvements from ventilation very uncertain. The graphs underpin the importance of refurbishing holistically as the major impact comes from a combination of improvements and not from any stand-alone measures with the sole exception of dynamic lighting from a reference situation on math skills.

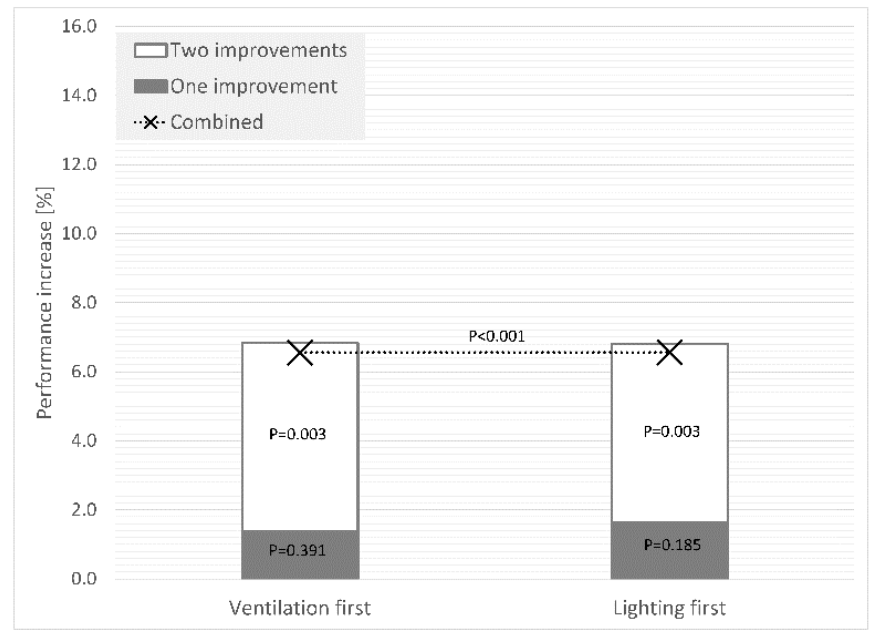


461

462

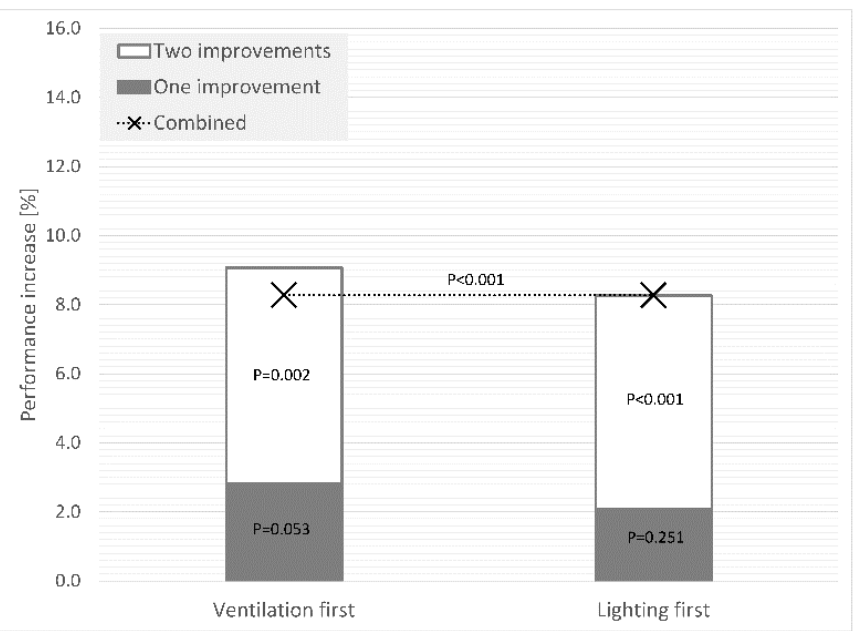

463

464 Fig. 11. CONC as a metric for concentration. Expected performance increase based on higher ventilation rate or changing to dynamic lighting or doing both. Significance level 0.01 (two-tailed).

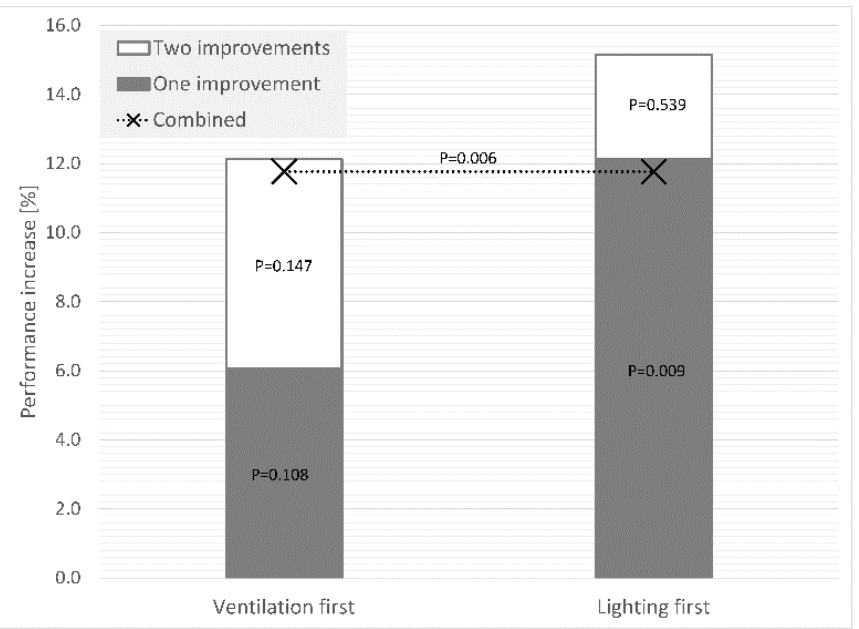


Fig. 12. Subtraction and multiplication tests as a metric for math abilities. Expected performance increase based on higher ventilation rate or changing to dynamic lighting or doing both. Significance level 0.01 (two-tailed).

\subsection{Questionnaires}

474

475

476

477

478

479

480

481

482

At the end of each test week, the pupils gave feedback on the perceived indoor climate. Table 8 summarizes the results for each test condition. In general, the feedback shows little impact from the four test conditions, which renders the results largely inconclusive. The classrooms were assessed to be too warm, which corresponds well with the verbal feedback from the teachers and the measured air temperatures, which started at $+24^{\circ} \mathrm{C}$ and trending towards $22^{\circ} \mathrm{C}$ in the final week. The pupils seem to be indifferent to the change in ventilation flow rate, which is positive in terms of both draught and noise and may be due to the diffuse ceiling ventilation concept. The noise score is towards the negative side, but this is probably due to the pedagogic approach with a large share of work in teams and therefore a lot of human background noise. In terms of perceived air quality, lighting conditions and motivation there were no changes to be detected.

\section{Table 8}

Questionnaire feedback from pupils from each test week merged into four test conditions

\begin{tabular}{lrrrr}
\hline & Week 1 & Week 2 & Week 3 & Week 4 \\
& 3.9l/s_2900K & 3.9l/s_4900K & 10.6l/s_2900K & 10.6l/s_4900K \\
& Mean \pm SD & Mean \pm SD & Mean \pm SD & Mean \pm SD \\
\hline Wellbeing in school: bad(1) - great(5) & $3.8 \pm 0.7$ & $3.8 \pm 0.7$ & $3.7 \pm 0.8$ & $3.9 \pm 0.9$ \\
Wellbeing outside school: bad(1) - great(5) & $4.3 \pm 0.7$ & $4.2 \pm 0.8$ & $4.1 \pm 0.9$ & $4.2 \pm 0.8$ \\
Classroom was: bad(1) - great(5) & $3.4 \pm 0.9$ & $3.2 \pm 0.9$ & $3.3 \pm 0.9$ & $3.4 \pm 0.8$ \\
Too warm(1) - Not too warm(5) & $2.7 \pm 1.2$ & $2.5 \pm 1.2$ & $2.9 \pm 1.3$ & $3.1 \pm 1.4$ \\
Too cold(1) - Not too cold(5) & $4.3 \pm 0.8$ & $4.4 \pm 0.8$ & $4.3 \pm 0.9$ & $4.2 \pm 0.9$ \\
\hline
\end{tabular}




\begin{tabular}{|c|c|c|c|c|}
\hline Draught(1) - No draught(5) & $4.3 \pm 1.0$ & $4.3 \pm 1.0$ & $4.2 \pm 1.0$ & $4.3 \pm 0.9$ \\
\hline Air was stuffy(1) - Air was fresh(5) & $3.0 \pm 1.2$ & $2.8 \pm 1.3$ & $2.8 \pm 1.2$ & $2.9 \pm 1.2$ \\
\hline Too noisy(1) - Quiet(5) & $2.6 \pm 1.1$ & $2.7 \pm 1.1$ & $2.8 \pm 1.0$ & $2.8 \pm 1.1$ \\
\hline Too bright(1) - Not too bright(5) & $3.8 \pm 1.2$ & $3.6 \pm 1.2$ & $3.9 \pm 1.0$ & $3.7 \pm 1.1$ \\
\hline Too dark(1) - Not too dark(5) & $4.4 \pm 0.9$ & $4.3 \pm 0.8$ & $4.1 \pm 0.9$ & $4.2 \pm 1.0$ \\
\hline Headache(1) - No headache(5) & $3.5 \pm 1.5$ & $3.3 \pm 1.4$ & $3.3 \pm 1.3$ & $3.3 \pm 1.3$ \\
\hline Concentration was: difficult(1) - easy(5) & $3.6 \pm 1.0$ & $3.3 \pm 1.0$ & $3.2 \pm 1.0$ & $3.4 \pm 1.1$ \\
\hline Sleepy(1) - Awake(5) & $3.7 \pm 1.1$ & $3.6 \pm 1.2$ & $3.6 \pm 1.3$ & $3.7 \pm 1.2$ \\
\hline Feeling like: not working(1) - working(5) & $3.8 \pm 1.1$ & $3.8 \pm 1.1$ & $3.8 \pm 1.0$ & $3.9 \pm 1.1$ \\
\hline Feeling not well(1) - Feeling well(5) & $4.1 \pm 0.9$ & $3.8 \pm 1.0$ & $4.0 \pm 1.0$ & $4.0 \pm 1.0$ \\
\hline
\end{tabular}

\section{Discussion}

\subsection{Main findings}

The aim of the study was to examine the effect in the pupils' cognitive performance and satisfaction with the indoor environment by changing their classrooms from having low ventilation rates and constant warm lighting to higher ventilation rates and dynamic cool lighting.

Out of the five contrasting scenarios, the move to higher ventilation rates and dynamic cool lighting was especially interesting, as both d2-test (TOT ERR and CONC) and math test improved significantly $(P<0.001, P<0.006)$, even considering the Bonferroni correction. The results of the individual measures, higher ventilation rates or dynamic lighting, point in the same positive direction, but was not statistically significant in all cases. Application of the Bonferroni correction changed significance of only one performance metric in one scenario, as denoted by the single asterisk $\left({ }^{*}\right)$ in Table 5 , and we did not put emphasis on this metric anyway due to the extremely small sample size.

The individual effect of higher ventilation rate was overall lower than expected and not always significant. For each $1 \mathrm{l} / \mathrm{s}$ per person ventilation increase the effect amounted to an overall average of 0.6\%. In comparison, others have published significant performance increases of $0.5 \%$ (math scores, range 0.9-7.1 I/s per person) [34], 1.1\% (math and language tasks, range 1.7-6.6 I/s per person) [4] and 
504

505

506

507

508

509

510

511

512

513

514

515

about 2\% (math and language tasks, range 3-9.5 l/s per person) [33]. The low effect is probably due to the relatively satisfactory ventilation rate in the reference condition (3.9 I/s person, approx. cat III [21]). The effect of dynamic lighting is low and insignificant for low ventilation rate, but increases to $6.1 \%$ (CONC) during higher ventilation rates and CO2-levels of approx. 800-900 ppm. This result concurs with a published study, where schoolchildren's concentration performance also increased significantly when given $1000 \mathrm{Ix}$ at $6500 \mathrm{~K}$ rather than 300 lux at $3000 \mathrm{~K}$ [18].

The Baddeley-test did not show any significant difference throughout the experiment. This is consistent with Wargocki \& Wyon [8], who used the same type of test in a similar study concerning ventilation flow rate and temperature. One reason could be that the test was too difficult for the age group or the eight minute period was too short. Petersen et al. [4] did find a significant $(P=0.04)$ improvement by the use of a Baddeley-test when pupils were given higher ventilation flow rate. But we noticed a major difference in the average score of 'Correct answers', being 62 in the study by Petersen and only 37 in this study. The higher score might be caused by age difference because in Petersen's study the population only consisted of $5^{\text {th }}$ graders. Furthermore, two more minutes were given compared to this experiment. Thus, no conclusions can be drawn from the Baddeley test results.

Prior to the study, we hypothesized that the combined effect of lighting and ventilation would not add up or boost the final results. Rather we hypothesized that a certain cancellation effect would occur, making it hard to find statistically significant results when lighting was combined with ventilation or vice versa. In Fig. 10, Fig. 11 and Fig. 12 the incremental positive performance changes due to either higher ventilation rate or dynamic cool lighting or combinations hereof are depicted. The figures illustrate that the total positive performance change from combined measures matches the summed up effect of individual measures. The exact contribution of the individual measures is uncertain due to the statistical significance level, but the d2-test results in Fig. 10 and Fig. 11 show that higher ventilation rate or dynamic lighting individually cause approx. the same effect on the pupil's cognitive performance, but in 
combination they boost one-another. In the math test results in Fig. 12 the measures seems to add up or even have some canceling effect, but the statistical significance here is low. Thus, the hypothesis is partly contradicted and partly supported by the results.

The results indicate that neither higher ventilation rate nor dynamic lighting as individual measures provide the full potential performance increase. Rather the results support the notion that the indoor climate parameters support one-another, and to gain the full potential of a refurbishment, it is imperative to consider the indoor climate from a holistic perspective.

\subsection{Limitations}

The data was pooled to create sample sizes as big as possible. Considering the physical adjacency, orientation and resemblance of the classrooms, we consider this statistically acceptable, but the effect of the teacher-pupil relation was obscured. Very light filtration of the test responses was implemented and only for obvious reasons: pupils showing signs of being deeply un-motivated with only very few responses or with tests badly doodled or with expressions of strong dislike of the whole situation. Thus, only 1-3 pupils in each dataset was discarded. Another filter was applied to the first and last line in every d2-test because many tests showed signs of premature start or delayed finish.

Great care was taken to avoid positive learning effects by rehearsing each test at least eight times before the real performance tests began. The cross-over periods were designed to eliminate the effect but we cannot completely disregard that some of the effect, especially in scenario 5 with data from early and late test weeks, is due to a positive learning curve. But we argue that the initial comprehensive and repetitive rehearsals should have made the students reach their maximum proficiency prior to the real tests and minimized the effect..On the opposite, fatigue caused by repetition was a bigger concern. Fatigue would be partly evident by the last four questions in the questionnaire relating to motivation but no trend of decreasing motivation could be observed. Thus, we did not find evidence of fatigue. 
The pupils knew they were being tested - in some respects the rigorous test regime collided with the pedagogic teaching methods that the pupils were used to - so it was impossible to hide the fact from them. Neither pupils, nor teachers knew which test condition they had a given week, but the colour temperature of the lighting fixtures and to some extent the perceived air quality was impossible to disguise. The $2 x$ cross-over experimental design, however, helped in obscuring any patterns to the test subjects and by running each test condition for at least three full school days prior to the first performance test the pupils acclimatized and minimized any carry-over effect. The questionnaire did not reveal either that the pupils noticed any changes to the air quality or lighting conditions.

We sacrificed the double-blind test regime even though it would have carried more power, because we deemed the risk of jeopardizing the entire experimental operation too high if we as researchers did not keep a close record of everything.

The questionnaire did not seem to capture the real feeling of the pupils. This is, however, in alignment with literature $[4,8,35]$ where very little evidence was found that the pupil's self-evaluation reflects the actual indoor climate conditions.

One important source of error was the daylight entering from the windows. The dynamic cool lighting was designed to mimic daylight and was therefore not as affected by additional daylight as the constant warm lighting was. We tried to minimize the effect by conducting the experiment in October and November where it is quite dark and overcast in Denmark, but the reported findings with the two lighting conditions might have been even more clear if the warm lighting conditions had not been 'contaminated' by daylight. Using the shading was not a viable option because it would substantially aggravate the learning environment. We do not have reliable daylight data to compensate for the effect, but in real schools the lighting system is also "contaminated" with daylight. Consequently, we regard the test results to be conservative and to be reflecting the effect that will be observable in real schools. 
The temperature was not constant during all the tests in all classes and this may have influenced the result as temperature is a key factor for work performance. But by the process of aggregating tests from different classes from different days into scenarios, the temperature differences are leveled out. Thus, in the scenarios where ventilation rate was increased (scenario 3-5) the temperature dropped by approx. $1^{\circ} \mathrm{C}$.

According to the thermal comfort model by Seppanen et al. [36], this amounts to a relative performance increase of $0.6 \%$ which concurs closely to Haverinen-Shaughnessy's study [34] who found $0.5 \%$ per $1^{\circ} \mathrm{C}$ decrement. 2\% was found by Wargocki \& Wyon [33]. Thus, a minor part of the performance increment found in the scenarios with higher ventilation rate is probably due to increased thermal comfort. In temperate climates, this inter-dependency is most often positive, but in warmer climates care should be taken to avoid that higher ventilation rates negatively affect thermal summer comfort and cannibalizes the performance improvement from higher ventilation rates.

\subsection{Future research}

This study focuses only on the inter-relations of two indoor environmental quality parameters: ventilation and lighting and only at specific levels. Future research should aim at determining the critical levels of these IEQ parameters where further improvement does not reflect in the student's performance; also because improved ventilation and lighting consumes more energy. Acoustics might also be included as an important IEQ aspect that is often considered when refurbishments are planned. Also further evidence for the conclusions should be gained by increasing the sample size and extent the investigation to include other academic skills, such as creative thinking and project work. 
595

596

597

598

599

600

601

602

603

604

605

606

607

608

609

610

611

612

613

614

615

616

617

618

\section{Conclusion}

This article reports on a field study where 92 pupils between the age of 10 and 12 years have been tested in processing speed, concentration, logical reasoning and math skills while they were subjected to different ventilation rates and lighting conditions. The tests were selected to measure the performance of various cognitive processes in the pupils. The experiment was designed as two $2 \times 2$ crossovers where the lighting was changed from constant warm light with a correlated colour temperature of $2900 \mathrm{~K}$ and illuminance 450 lux to a dynamic cool light with a maintained average of CCT $4900 \mathrm{~K}$ and 750 lux. Each $2 \times 2$ crossover was tested at both low ( $3.9 \mathrm{l} / \mathrm{s}$ per person) and high ventilation rate (10.6 l/s per person), Five statistical scenarios were constructed to contrast the different indoor climate test conditions. The scenarios showed that processing speed $(6.6 \%, \mathrm{P}<0.001)$, concentration $(8.3 \%, \mathrm{P}<0.001)$ and math skills $(11.8 \%, \mathrm{P}<0.006)$, improved the most in the combined scenario with high ventilation rate and dynamic cool lighting. The logical reasoning test did not show significant changes in any of the scenarios. The scenarios also indicated that the processing speed and concentration metrics were boosted when both ventilation and lighting was improved. The math test indicated a more equal balance between the effect of lighting and ventilation, perhaps even some canceling effect. The weekly questionnaires showed a general satisfaction with the environmental conditions, but dissatisfaction concerning overheating, air quality and noise was persistent irrespective of the actual indoor conditions. However, this is most likely due to the formulation of the questions and the pupils having difficulty reflecting on their indoor environment.

\section{Declaration of interest}

In accordance with Elsevier policy and our ethical obligations as researchers, we report that the main author is partly employed by the Saint-Gobain Group, but has conducted this research independently by virtue of his affiliation with the University. We declare that neither the school, nor the refurbishing 
companies have had any influence, nor attempted to gain influence on the experimental design, results and/or conclusions of this study in any way or at any time.

\section{Acknowledgements}

The authors are grateful for the access to the school and for the commitment of the school management, teachers and pupils, especially with regard to the timely execution of the performance tests. The authors also want to extend their gratitude to Saint-Gobain aereNmore and Brainlit for the planning and refurbishing of the school and granting access to their indoor climate control systems and to the anonymous reviewers for detailed comments that resulted in an improvement of the original manuscript.

\section{Note}

1. Concept developed by Saint-Gobain aereNmore, Nordic countries and Brainlit AB, Sweden. Research conducted independently.

\section{References}

[1] P. Wargocki, D.P. Wyon, The Effects of Outdoor Air Supply Rate and Supply Air Filter Condition in Classrooms on the Performance of Schoolwork by Children (RP-1257), HVAC\&R Res. 13 (2007) 165-191. doi:10.1080/10789669.2007.10390950.

[2] U. Haverinen-Shaughnessy, D.J. Moschandreas, R.J. Shaughnessy, Association between substandard classroom ventilation rates and students' academic achievement, Indoor Air. 21 (2011) 121-131. doi:10.1111/j.1600-0668.2010.00686.x.

[3] Z. Bakó-Biró, D.J. Clements-Croome, N. Kochhar, H.B. Awbi, M.J. Williams, Ventilation rates in schools and pupils' performance, (2012). doi:10.1016/j.buildenv.2011.08.018. 
643

644

645

646

647

648

649

650

651

652

653

654

655

656

657

658

659

660

661

662

663

664

665

666

[4] S. Petersen, K.L. Jensen, A.L.S. Pedersen, H.S. Rasmussen, The effect of increased classroom ventilation rate indicated by reduced $\mathrm{CO} 2$ concentration on the performance of schoolwork by children, Indoor Air. 26 (2016) 366-379. doi:10.1111/ina.12210.

[5] L. Heschong, R.L. Wright, S. Okura, Daylighting impacts on human performance in school, J. Illum. Eng. Soc. 31 (2002) 101-114. doi:10.1080/00994480.2002.10748396.

[6] W.E. Hathaway, Effects of School Lighting on Physical Development and School Performance, J. Educ. Res. 88 (1995) 228-242. doi:10.1080/00220671.1995.9941304.

[7] M.S. Mott, D.H. Robinson, A. Walden, J. Burnette, A.S. Rutherford, Illuminating the effects of dynamic lighting on student learning, SAGE Open. (2012). doi:10.1177/2158244012445585.

[8] P. Wargocki, D.P. Wyon, The effects of moderately raised classroom temperatures and classroom ventilation rate on the performance of schoolwork by children (RP-1257), HVAC R Res. 13 (2007) 193-220. doi:10.1080/10789669.2007.10390951.

[9] V. Hongisto, A model predicting the effect of speech of varying intelligibility on work performance, Indoor Air. 15 (2005) 458-468. doi:10.1111/j.1600-0668.2005.00391.x.

[10] B.M. Shield, J.E. Dockrell, The effects of environmental and classroom noise on the academic attainments of primary school children, J. Acoust. Soc. Am. 123 (2008) 133-144. doi:10.1121/1.2812596.

[11] M. Klatte, J. Hellbrück, Effects of Classroom Acoustics on Performance and Well-Being in Elementary School Children : A Field Study Effects of classroom acoustics on performance and well- being in elementary school children : A field study, (2016) 1-9. doi:10.1177/0013916509336813.

[12] C.K. Tanner, Effects of school design on student outcomes, J. Educ. Adm. 47 (2009) 381-399. doi:10.1108/09578230910955809.

[13] P. Barrett, Y. Zhang, J. Moffat, K. Kobbacy, A holistic, multi-level analysis identifying the impact of 
667

668

669

670

671

672

673

674

675

676

677

678

679

680

681

682

683

684

685

686

687

688

689

690

classroom design on pupils' learning, Build. Environ. (2013). doi:10.1016/j.buildenv.2012.09.016.

[14] P.V. Dorizas, M.N. Assimakopoulos, M. Santamouris, A holistic approach for the assessment of the indoor environmental quality, student productivity, and energy consumption in primary schools, Environ. Monit. Assess. 187 (2015) 1-18. doi:10.1007/s10661-015-4503-9.

[15] P. Barrett, F. Davies, Y. Zhang, L. Barrett, The impact of classroom design on pupils' learning: Final results of a holistic, multi-level analysis, Build. Environ. 89 (2015) 118-133. doi:10.1016/j.buildenv.2015.02.013.

[16] I. Knez, C. Kers, Effects of indoor lighting, gender, and age on mood and cognitive performance, Environ. Behav. 32 (2000) 817-831. doi:10.1177/0013916500326005.

[17] A.U. Viola, L.M. James, L.J.M. Schlangen, D.J. Dijk, Blue-enriched white light in the workplace improves self-reported alertness, performance and sleep quality, Scand. J. Work. Environ. Heal. (2008). doi:10.5271/sjweh.1268.

[18] P. Sleegers, B. Van Der Zande, Lighting affects students' concentration positively: Findings from three Dutch studies, Light. Res. Technol. 45 (2013) 159-175. doi:10.1177/1477153512446099.

[19] K. Konis, Field evaluation of the circadian stimulus potential of daylit and non-daylit spaces in dementia care facilities, Build. Environ. 135 (2018) 112-123. doi:10.1016/j.buildenv.2018.03.007.

[20] S.W. Lockley, G.C. Brainard, C.A. Czeisler, High sensitivity of the human circadian melatonin rhythm to resetting by short wavelength light, J. Clin. Endocrinol. Metab. 88 (2003) 4502-4505. doi:10.1210/jc.2003-030570.

[21] EN 16798-2, Energy performance of buildings - Ventilation for buildings - Part 2: Interpretation of the requirements in EN 16798-1, (2019).

[22] C.A. Hviid, S. Svendsen, Experimental study of perforated suspended ceilings as diffuse ventilation air inlets, Energy Build. 56 (2013) 160-168. doi:10.1016/j.enbuild.2012.09.010.

[23] S. Petersen, N.U. Christensen, C. Heinsen, A.S. Hansen, Investigation of the displacement effect of 
691

692

693

694

695

696

697

698

699

700

701

702

703

704

705

706

707

708

709

710

711

712

713

714

a diffuse ceiling ventilation system, Energy Build. 85 (2014) 265-274.

doi:10.1016/j.enbuild.2014.09.041.

[24] M.H. Kristensen, J.S. Jensen, Impact of diffuse ceiling ventilation systems on indoor environmental quality in classrooms, 2015.

[25] S. Lestinen, S. Kilpeläinen, R. Kosonen, J. Jokisalo, H. Koskela, Experimental study on airflow characteristics with asymmetrical heat load distribution and low-momentum diffuse ceiling ventilation, Build. Environ. 134 (2018) 168-180. doi:10.1016/j.buildenv.2018.02.029.

[26] EN12464-1, Light and lighting - Lighting of work places - Part 1: Indoor work places, Eur. Comm. Stand. (2011).

[27] EN ISO 3382-2, Acoustics - Measurement of room acoustic parameters - Part 2: Reverberation time in ordinary rooms - Corrigendum, Eur. Comm. Stand. (2009) 1-2.

[28] IC-Meter, (2019). www.ic-meter.com.

[29] M.E. Bates, E.P. Lemay, The d2 Test of Attention: Construct validity and extensions in scoring techniques, J. Int. Neuropsychol. Soc. 10 (2004). doi:10.1017/S135561770410307X.

[30] R. Wassenberg, J.G.M. Hendriksen, P.P.M. Hurks, F.J.M. Feron, E.H.H. Keulers, J.S.H. Vles, J. Jolles, Development of inattention, impulsivity, and processing speed as measured by the $\mathrm{d} 2 \mathrm{test}$ : Results of a large cross-sectional study in children aged 7-13, Child Neuropsychol. 14 (2008) 195210. doi:10.1080/09297040601187940.

[31] A. Fernández-Castillo, M.J. Caurcel, State test-anxiety, selective attention and concentration in university students, Int. J. Psychol. 50 (2015) 265-271. doi:10.1002/ijop.12092.

[32] A.D. Baddeley, A 3 min reasoning test based on grammatical transformation, Psychon. Sci. 10 (1968) 341-342. doi:10.3758/BF03331551.

[33] P. Wargocki, D.P. Wyon, Effects of HVAC on student performance, ASHRAE J. 48 (2006) 23-28.

[34] U. Haverinen-Shaughnessy, R.J. Shaughnessy, Effects of Classroom Ventilation Rate and 
Temperature on Students' Test Scores, PLoS One. 10 (2015). doi:10.1371/journal.pone.0136165.

[35] V. De Giuli, O. Da Pos, M. De Carli, Indoor environmental quality and pupil perception in Italian primary schools, Build. Environ. 56 (2012) 335-345. doi:10.1016/j.buildenv.2012.03.024.

[36] O. Seppänen, W.J. Fisk, Q.H. Lei, Room temperature and productivity in office work, in: HB 2006 Heal. Build. Creat. a Heal. Indoor Environ. People, Proc., 2006: pp. 243-247. 
- Schoolchildren's performance is affected by ventilation rate and lighting conditions

- The effect of individual measures was small compared to combined effect

- Neither improved ventilation rate, nor lighting conditions should be individual measures

- Combine improved ventilation rate and lighting conditions to boost performance

- The results support a holistic view on indoor environmental refurbishment 


\section{Declaration of interest}

In accordance with Elsevier policy and our ethical obligations as researchers, we report that the main author is partly employed by the Saint-Gobain Group, but has conducted this research independently by virtue of his affiliation with the University. We declare that neither the school, nor the refurbishing companies have had any influence, nor attempted to gain influence on the experimental design, results and/or conclusions of this study in any way or at any time. 